\title{
Antibacterial Behavior of Chitosan-Sodium Hyaluronate-PEGDE Crosslinked Films
}

\author{
Martha Gabriela Chuc-Gamboa ${ }^{1}\left(\mathbb{D}\right.$, Carolina María Cámara Perera ${ }^{1}$, Fernando Javier Aguilar Ayala ${ }^{1}{ }^{1}$, \\ Rossana Faride Vargas-Coronado ${ }^{2}$, Juan Valerio Cauich-Rodríguez ${ }^{2, * \mathbb{D}}$, Diana María Escobar-García ${ }^{3}$, \\ Luis Octavio Sánchez-Vargas ${ }^{4}\left(\mathbb{D}\right.$, Neith Pacheco ${ }^{5}$ and Julio San Román del Barrio ${ }^{6}$
}

Citation: Chuc-Gamboa, M.G.;

Cámara Perera, C.M.; Aguilar Ayala, F.J. Vargas-Coronado, R.F.;

Cauich-Rodríguez, J.V.;

Escobar-García, D.M.;

Sánchez-Vargas, L.O.; Pacheco, N.; San Román del Barrio, J. Antibacterial Behavior of Chitosan-Sodium Hyaluronate-PEGDE Crosslinked Films. Appl. Sci. 2021, 11, 1267. https://doi.org/10.3390/app1103 1267

Academic Editor: Elia Marin Received: 29 December 2020 Accepted: 26 January 2021

Published: 30 January 2021

Publisher's Note: MDPI stays neutral with regard to jurisdictional claims in published maps and institutional affiliations.

Copyright: (c) 2021 by the authors. Licensee MDPI, Basel, Switzerland This article is an open access article distributed under the terms and conditions of the Creative Commons Attribution (CC BY) license (https:// creativecommons.org/licenses/by/ $4.0 /$ )
1 Facultad de Odontología, Universidad Autónoma de Yucatán, Calle 61 A \#492 A x 90 y Av. Itzáes, Centro., Mérida C.P. 97000, Mexico; martha.chuc@correo.uady.mx (M.G.C.-G.); carolina_1296@hotmail.com (C.M.C.P.); faguilar@correo.uady.mx (F.J.A.A.)

2 Unidad de Materiales, Centro de Investigación Científica de Yucatán, Calle 43 No. 130 x 32 y 34 , Colonia Chuburná de Hidalgo, Mérida C.P. 97205, Mexico; ross@cicy.mx

3 Laboratorio de Ciencias Básicas, Facultad de Estomatología, Universidad Autónoma de San Luis Potosí, Ave. Dr. Manuel Nava No. 2, Zona Universitaria, San Luis C.P. 78290, Mexico; diana.escobar@uaslp.mx

4 Laboratorio de Microbiología, Facultad de Estomatología, Universidad Autónoma de San Luis Potosí, Ave. Dr. Manuel Nava No. 2, Zona Universitaria, San Luis C.P. 78290, Mexico; lo.sanchezvargas@gmail.com

5 Centro de Investigación y Asistencia en Tecnología y Diseño del Estado de Jalisco, A.C. Parque Científico Tecnológico de Yucatán, km 5.5 Carretera, Sierra Papacal-Chuburná, Chuburná C.P. 97302, Mexico; npacheco@ciatej.mx

6 Instituto de Ciencia y Tecnología de Polímeros, Juan de la Cierva, 3, Madrid C.P. 28006, Spain; jsroman@ictp.csic.es

* Correspondence: jvcr@cicy.mx; Tel.: +52-999-942-8330

Abstract: Chitosan is a natural polymer that can sustain not only osteoblast adhesion and proliferation for bone regeneration purposes, but it is also claimed to exhibit antibacterial properties towards several Gram-positive and Gram-negative bacteria. In this study, chitosan was modified with sodium hyaluronate, crosslinked with polyethylene glycol diglycidyl ether (PEGDE) and both osteoblast cytotoxicity and antibacterial behavior studied. The presence of sodium hyaluronate and PEGDE on chitosan was detected by FTIR, XRD, and XPS. Chitosan (CHT) films with sodium hyaluronate crosslinked with PEGDE showed a better thermal stability than pristine hyaluronate. In addition, osteoblast cytocompatibility improved in films containing sodium hyaluronate. However, none of the films exhibit antimicrobial activity against Escherichia coli, Enterococcus faecalis, and Staphylococcus aureus while exhibiting low to mild activity against Salmonella typhimurion.

Keywords: chitosan; sodium hyaluronate; PEGDE; antibacterial; Escherichia coli; Enterococcus faecalis; Staphylococcus aureus; Salmonella typhimurion

\section{Introduction}

Chitosan (CHT), the main derivative of chitin, is a natural linear polycation that exhibits biocompatibility [1], anti-inflammatory [2], antimicrobial [3,4], hypocholesterolemic [5], immunostimulant [6], antitumor activity [7], antioxidant, and anticancer properties [8]. However, in order to improve some of their properties it tends to be modified by using the free amino groups on the D-glucosamine repeating unit. In this way, novel crosslinking agents has been used to improve their mechanical properties or sometimes specific functional groups have been incorporated to render them more water soluble. In addition, several approaches made use of the addition of a second synthetic or natural polymer including hyaluronic acid or its sodium salt. Hyaluronic acid (HA) is a glycosaminoglycan consisting of repeating units of a linear polyanionic polysaccharide composed of alternating disaccharide units of $\alpha-1,4$-d-glucuronic acid and $\beta-1,3-N$-acetyl-d-glucosamine [9,10]. It is found in the extracellular matrix (ECM) of all living tissues, in different concentrations 
and molecular weights, being more abundant in tissues subjected to mechanical loads, such as cartilage, dermis, and vocal cords [11]. HA plays a key role in cell division and migration, angiogenesis, wound healing, and tissue regeneration. Due to its biocompatibility, biodegradability, and susceptibility to chemically modification, it is of great interest for its potential in the field of bone tissue engineering [11]. A way to modify the properties of a polymer with hyaluronic acid is through polyelectrolyte complexation where HA can be combined with natural polymers such as collagen or chitosan [12,13].

In this regard, it has been reported that the introduction of hyaluronic acid on chitosan scaffolds, improves cell proliferation, and extracellular matrix synthesis (ECM) [14]. In addition, chitosan/acid hyaluronic sponges loaded with fibrin nanoparticles and VEGF promoted endothelial cell proliferation as well as capillary tube formation [15]. Chitosanco-Hyaluronic acid cryohydrogels used as a scaffolds showed higher cell proliferation by increasing hyaluronic acid content [16]. Similarly, CHT/HA scaffolds promoted cellular adhesion of chondrocytes [17], pre-osteoblast [18], and have potential uses in cartilage for tissue engineering applications. Finally, Chitosan/HA blends have been suggested as a stable anti-fouling surface [19].

Chitosan is also identified as a potent antimicrobial and antibiofilm polymer $[4,20]$. These properties are attributed to the electrostatic interactions between the positively charged group of chitosan and the negatively charged components of the biofilm matrix such as DNA, proteins, and lipids [20]. In addition, the antimicrobial activity of chitosan can be influenced by factors such as molecular weight, degree of deacetylation, $\mathrm{pH}$, temperature, and solvent of the chitosan, among others [3,21,22].

The antimicrobial properties of CHT/HA have been reported as an unfilled matrix or loaded with bactericidal particles (silver, $\mathrm{ZnO}$ ), antibiotics (gentamicin, penicillin $\mathrm{G}$ ), and antimicrobial peptides (AMP). For example, interpenetrated hydrogels made of chitosan and hyaluronan exhibited activity against Staphylococcus aureus [23-25].

Therefore, the combination of CHT and HA is expected to render a polymer blend with improved osteocompatibilty. However, it is not clear if this association will affect the antibacterial properties of CHT as it is known that CHT kills Gram-negative and Gram-positive bacteria [3] by forming complexes with the anionic phospholipid bacterial membrane $[26,27]$.

\section{Materials and Methods}

\subsection{Materials}

Chitosan (CHT) with a medium molecular weight and a degree of deacetylation of $84.1 \%$, polyethylene glycol diglycidyl ether (Mn 500), and glutaraldehyde (GA) solution Grade II, 25\% in $\mathrm{H}_{2} \mathrm{O}$ were purchased from Sigma-Aldrich. Sodium Hyaluronate ( $\left.\mathrm{HNa}\right)$ Oral Grade LMW was obtained from Bioibérica (Barcelona, Spain) whereas acetic acid was provided by J.T. Baker (Xalostoc, Mexico). MTS CellTiter $96{ }^{\circledR}$ Aqueous Non-Radioactive Cell Proliferation kit was supplied by Promega (Madison, WI, USA). Human osteoblast hFOB1.19 from ATCC ${ }^{\circledR}$ CRL-11372 ${ }^{\mathrm{TM}}$ (Manassas, VA, USA) were cultured in Dulbecco's modified Eagle's medium (DMEM) provided by Biowest (Riverside, MO, USA). For the antimicrobial assays, Escherichia coli ATCC 25922, Enterococcus faecalis ATCC 51299, Staphylococcus aureus ATCC 25923, and Salmonella typhimurion ATCC 14028 were used.

\subsection{Preparation of Chitosan-HNa Films}

Chitosan scaffolds were prepared by dissolving CHT in $0.4 \mathrm{M}$ acetic acid for one hour and then $\mathrm{HNa}$, corresponding to concentrations of $15 \%$ and $30 \%$, was added and stirred for another hour. The final solution was poured into plastic Petri dishes and dried at $25^{\circ} \mathrm{C}$, for approximately 7 days, until the acetic acid was completely evaporated. The uncrosslinked films were neutralized with sodium hydroxide solution ( $5 \mathrm{wt} . \%)$, washed with distilled water, and dried again at $25^{\circ} \mathrm{C}$. Crosslinked films were obtained by crosslinking with either PEGDE (PEGDE1: $0.114 \mathrm{mM}(50 \mu \mathrm{L})$, PEGDE2: $0.228 \mathrm{mM}(100 \mu \mathrm{L})$, PEGDE3: $0.342 \mathrm{mM}$ $(150 \mu \mathrm{L})$, and glutaraldehyde (GA) as reported before [28]. Opaque samples were obtained 
initially, and they became transparent after $\mathrm{NaOH}$ neutralization. Table 1 summarizes the composition studied.

Table 1. Composition of chitosan (CHT) films, $\mathrm{CHT} / \mathrm{HNa}$ at $15 \%$ and $30 \%$ films crosslinked with glutaraldehyde (GA) and polyethylene glycol diglycidyl ether (PEGDE).

\begin{tabular}{ccccc}
\hline Films & $\mathbf{\%}$ & $\begin{array}{c}\text { CHT } \\
\mathbf{~ m g}\end{array}$ & $\begin{array}{c}\text { HNa } \\
\mathbf{m g}\end{array}$ & $\begin{array}{c}\text { Crosslinking Agent } \\
\boldsymbol{~} \mathbf{L}\end{array}$ \\
\hline Chitosan- Sodium Hyaluronate & 15 & 200 & 30 & - \\
Chitosan- Sodium Hyaluronate & 30 & 200 & 60 & - \\
Chitosan- Sodium Hyaluronate-PEGDE 1 & 15 & 200 & 30 & 50 \\
Chitosan- Sodium Hyaluronate-PEGDE 1 & 30 & 200 & 60 & 50 \\
Chitosan- Sodium Hyaluronate-PEGDE 2 & 15 & 200 & 30 & 100 \\
Chitosan- Sodium Hyaluronate-PEGDE 2 & 30 & 200 & 60 & 100 \\
Chitosan- Sodium Hyaluronate-PEGDE 3 & 15 & 200 & 30 & 150 \\
Chitosan- Sodium Hyaluronate-PEGDE 3 & 30 & 200 & 60 & 150 \\
Chitosan- Sodium Hyaluronate-GA & 15 & 200 & 30 & 150 \\
Chitosan- Sodium Hyaluronate-GA & 30 & 200 & 60 & 150 \\
\hline
\end{tabular}

\subsection{Composition and Structural Characterization of PEGDE Crosslinked CHT/HNa Films}

\subsubsection{Fourier-Transform-Infrared Spectroscopy (FTIR)}

Fourier transform infrared (FTIR) spectra of the films were recorded by using a Thermo Scientific Nicolet 8700 FT-IR spectrometer (Madison, WI, USA) with Zinc Selenide attenuated total reflectance (ATR) accessory. The spectra were obtained in the spectral range of 4000 to $650 \mathrm{~cm}^{-1}$ averaging 100 scans with a resolution of $4 \mathrm{~cm}^{-1}$.

\subsubsection{Raman Spectroscopy}

Raman spectra were collected using the InVia ${ }^{\mathrm{TM}}$ Raman Renishaw microscope (Wottonunder-Edge, Gloucestershire). A $633 \mathrm{~nm}$ laser was used at 50\% power. The samples were examined in the spectral range of 100 to $3200 \mathrm{~cm}^{-1}$ with 2 accumulations, 1800 grid, $50 \times$ objective, with an exposure time of $10 \mathrm{~s}$.

\subsubsection{Thermogravimetric Analysis (TGA)}

Thermogravimetric analysis was performed in a TGA $8000^{\mathrm{TM}}$ from Perkin-Elmer (Waltham, MA, USA) in the temperature range $50-700{ }^{\circ} \mathrm{C}$ and under continuous flow of dry nitrogen at a heating rate of $10^{\circ} \mathrm{C} / \mathrm{min}$.

\subsubsection{X-ray Diffraction (XRD)}

X-ray diffraction patterns of films were analyzed using a Bruker D-8 Advance X-ray diffractometer (Karlsruhe, Germany) over a $2 \theta$ range from $5^{\circ}$ to $60^{\circ}$, a step size of 0.02 , a scan speed of $6 \mathrm{~s}, 40 \mathrm{mV}$, and $55 \mathrm{~mA}$.

\subsection{Surface Properties of PEGDE Crosslinked CHT/HNa Films}

\subsubsection{Scanning Electron Microscopy (SEM)}

The morphology of film surface was characterized by using a JEOL, JMS 6360LV (Akishima, Tokyo, Japan) with an accelerating voltage of $20 \mathrm{keV}$. The samples $(1 \mathrm{~cm}$ diameter $)$ were coated with a thin layer of gold in a Denton Desk II Sputter Coater (Moorestown, $\mathrm{NJ}$, USA) (50 s, $40 \mathrm{~mA}$ ) before the observation. In addition, Energy-dispersive X-ray spectroscopy (EDX) (Oxford Instruments, INCA X-Sight 7582, High Wycombe, UK) coupled with the microscope, was used to obtained elemental surface composition. At least three different locations (top, middle, and bottom) were scanned, and the average reported.

\subsubsection{X-ray Photoelectron Spectroscopy (XPS)}

Elemental composition on film surfaces was also obtained by X-ray Photoelectron Spectroscopy. The XPS analyses were performed using a Thermo Scientific K-Alpha X-ray 
Photoelectron Spectrometer (Waltham, MA, USA), equipped with an AlEs cathode, without erosion. Survey spectra were acquired over a binding energy range of 0 to $1100 \mathrm{eV}$, using a pass energy of $50 \mathrm{eV}$. High-resolution spectra for the C1s, O1s, N1s regions were also obtained. Elemental composition (at.\%) was calculated from the integrated intensities of the XPS peaks, which considered the atomic sensitivity factors of the instrument data system.

\subsubsection{Atomic Force Microscopy (AFM)}

To calculate the surface roughness of the samples (Ra), AFM analysis was performed using a Bruker INNOVA AFM scanning probe microscope (Santa Barbara, CA, USA.), with a commercial silicone tip (RTESP nanoprobe Bruker) at a resonance frequency of $300 \mathrm{kHz}$, a spring constant of $40 \mathrm{~N} / \mathrm{m}$, and $8 \mathrm{~nm}$ tip radius. A statistical analysis was conducted to obtain the roughness on the scanned $50 \mu \mathrm{m} \times 50 \mu \mathrm{m}$ area at the scanning frequency of $0.5 \mathrm{~Hz}$ while roughness was calculated for each subarea using the Nanoscope Analysis software. The statistical average and the standard deviation of the roughness of each type of sample was reported considering 12 measurements.

\subsubsection{Contact Angles}

A ramé-hart model 250 goniometer/tensiometer with DROPimage Advanced v2.8 (Succasunna, NJ, USA) was used to measure the contact angle on the surface of the chitosan films. For this, a $10 \mathrm{~mm} \times 60 \mathrm{~mm}$ film was placed on the measuring surface and then $5 \mu \mathrm{L}$ of either distilled water or Dulbecco's Modified Eagle's Medium (DMEM) were dispensed on the surface of the film and the measurements recorded at $25^{\circ} \mathrm{C}$. Ten replicates per sample were averaged, the image of the water or DMEM droplet was captured within $10 \mathrm{~s}$ of delivery. The contact angle was measured automatically using computer integrated software.

\subsection{Biological Studies}

\subsubsection{Cell Viability Assay}

The viability of human osteoblast ATCC hFOB1.19 cultured on the chitosan film was determined using the MTS assay. Before cell seeding, $10 \mathrm{mg}$ samples $(n=5)$ were sterilized by UV irradiation for 15 min each side and then seeded at $2 \times 10^{3}$ cells $/$ scaffolds in a 96-well plate. The seeded cells were incubated at $37^{\circ} \mathrm{C}, 5 \% \mathrm{CO}_{2}$, and $95 \%$ humidity for $48 \mathrm{~h}$. A positive control was included, which comprised cells with only culture medium $(\mathrm{C}+)$ and hydrogen peroxide as negative control $(\mathrm{C}-)$ with the target with MTS solution.

After $3 \mathrm{~h}$ of MTS incubation with the cells, the light absorbance at $490 \mathrm{~nm}$ was measured by a multi-well spectrophotometer (Thermo Scientific ${ }^{\mathrm{TM}}$ ) and subtracted from that of the controls to yield the corrected absorbance.

Cell adhesion was followed by SEM using both direct and indirect methods. Osteoblast $\left(2 \times 10^{4}\right.$ cells $\left./ \mathrm{mL}\right)$ were seeded in a 24 -well plate and then either grown on $10 \mathrm{mg}$ films for direct contact analysis or by using $300 \mu \mathrm{L}$ of extracts, obtained from each sample, and deposited on glass discs for indirect contact assay. For this, they were incubated at $37^{\circ} \mathrm{C}$, $5 \% \mathrm{CO}_{2}$ and $95 \%$ humidity for $48 \mathrm{~h}$. After osteoblast culture, samples were washed twice with PBS, and fixed in 25\% glutaraldehyde, for $2 \mathrm{~h}$. Subsequently, the samples were washed three times for 10 min with PBS and dehydrated in gradual series of ethanol (70, 80, 90\% and absolute ethanol) for $1 \mathrm{~h}$ for each percentage. The fixed cells were observed in a JEOL brand Scanning Electron Microscope, JSM-6360 LV, at different amplifications $(500 \times)$ using a voltage of $20 \mathrm{kV}$, on a cold stage at $-20^{\circ} \mathrm{C}$.

\subsubsection{Antimicrobial Activity Assays}

Two types of antimicrobial assays were performed. For the first method, Escherichia coli, Enterococcus faecalis, and Staphylococcus aureus were used. Each strain was cultured on blood agar media by simple striated method. Petri dishes were incubated during $12 \mathrm{~h}$ at $36^{\circ} \mathrm{C}$. For inoculum preparation, a sample of the strains were deposited in Falcon conical tubes containing $5 \mathrm{~mL}$ Mueller-Hinton broth and incubated again for $12 \mathrm{~h}$ at $36^{\circ} \mathrm{C}$. Then, 
three morphological similar CFU of each strain were placed on $5 \mathrm{~mL}$ of sterile $\mathrm{NaCl} 0.9 \%$ solution and adjusted to McFarland 0.5. This final, bacteria concentration was re-seeded on Petri culture dishes.

The Kirby-Bauer method was used to assess the bacterial sensibility of the CHT/HNa PEGDE crosslinked biomaterial. For this, a sterile swab was immersed in the inoculum and was deposited by simple striated method on agar Mueller-Hinton. After 3-5 min, $6 \mathrm{~mm}$ discs were placed on the agar surface and incubated at $35^{\circ} \mathrm{C}$ for $18-24 \mathrm{~h}$. Antibiotic impregnated Sensidiscs ${ }^{\mathrm{TM}}$ were used as control using Amoxicilin/clavulanic acid for E. coli, y Ciprofloxacin for E. faecalis, and Cefuroxim for S. aureus. An inhibitory halo higher than $8 \mathrm{~mm}$ was considered and inhibitor of bacterial growth.

For the second antimicrobial assay S. typhimurion was cultured in nutrient broth for reactivation at $37^{\circ} \mathrm{C}$ for $24 \mathrm{~h}$. Bacterial suspensions were prepared by diluting bacterial strains with Mueller-Hinton broth (MHB) prepared in Petri dishes using $100 \mu \mathrm{L}$ of the suspension of each bacterium separately at a concentration adjusted with saline solution of $105 \mathrm{CFU} / \mathrm{mL}$, and then the microorganisms were spread in the medium using a glass loop. Twenty-millimeter-diameter discs of pristine chitosan, CHT/HNa 15\%, CHT/HNa 15\%/GA, and CHT/HNa 15\%/PEGDE3 films were placed in Petri dishes containing culture medium, previously inoculated with Mueller Hinton microorganisms. The studied samples were incubated at $37^{\circ} \mathrm{C}$ for $24 \mathrm{~h}$ and their antimicrobial activity determined as negative or positive according to microorganism growth above or below the film when observed directly. To distinguish the presence or absence of bacterial growth in nontransparent films, $10 \mu \mathrm{L}$ of p-iodonitrotetrazolium chloride solution $(0.2 \mathrm{mg} / \mathrm{mL})$ was used as a growth indicator, after $5 \mathrm{~min}$ of incubation the presence of a red-pink color change was verified as an indicator microbial growth.

\section{Results and Discussion}

\subsection{Composition and Structure of CHT Films \\ 3.1.1. FTIR Spectroscopy}

FTIR spectra of films of pristine chitosan $(\mathrm{CHT})$, pristine sodium hyaluronate $(\mathrm{HNa})$, and mixtures of CHT/HNa, CHT/HNa-PEGDE are shown in Figure $1 \mathrm{a}(15 \% \mathrm{HNa})$ and Figure $1 \mathrm{~b}(30 \% \mathrm{HNa})$, (for clarity high quality FTIR individual spectra is reported in supplementary information, S1). Pristine chitosan (Figure 1a) showed the typical broad absorption between $3677 \mathrm{~cm}^{-1}$ and $3000 \mathrm{~cm}^{-1}$ (peaks at $3350 \mathrm{~cm}^{-1}$ and $3289 \mathrm{~cm}^{-1}$ ), which correlate with the $\mathrm{O}-\mathrm{H}$ (from chitosan and water) and $\mathrm{N}-\mathrm{H}$ vibration in $\mathrm{N}-\mathrm{H}_{2}$ groups. At $2921 \mathrm{~cm}^{-1}$ and $2852 \mathrm{~cm}^{-1}$ absorptions corresponding to stretching $\mathrm{C}-\mathrm{H}$ in $\mathrm{C}-\mathrm{H}_{2}$ and $\mathrm{C}-\mathrm{H}_{3}$ were observed. The absorption band at $1647 \mathrm{~cm}^{-1}$ was related to $\mathrm{C}=\mathrm{O}$ vibration in the amide $\mathrm{I}$. The band at $1558 \mathrm{~cm}^{-1}$ was attributed to $\mathrm{C}-\mathrm{N}$ and $\mathrm{N}-\mathrm{H}_{2}$ bending in amide II region. At $1419 \mathrm{~cm}^{-1}$, bands associated to $\mathrm{C}-\mathrm{H}_{2}$ bending were observed. At $1314 \mathrm{~cm}^{-1}$, the amide III appeared. Skeletal vibrations characteristic of the chitosan structure appeared at $1068 \mathrm{~cm}^{-1}$ and $1050 \mathrm{~cm}^{-1}$ (pyranose ring). Sodium Hyaluronate (Figure 1a) showed a broad band with a maximum at $3307 \mathrm{~cm}^{-1}$ for films and $3294 \mathrm{~cm}^{-1}$ for the powder, which were assigned to $\mathrm{N}-\mathrm{H}$ and O-H stretch absorptions. It was also observed a peak at $2905 \mathrm{~cm}^{-1}$ and $2868 \mathrm{~cm}^{-1}$ related to $\mathrm{CH}_{2}$. Absorptions at $1734 \mathrm{~cm}^{-1}$ was assigned to carboxylic acid/carboxylate while at $1606 \mathrm{~cm}^{-1}$ Amide I was observed, and Amide II observed as a small shoulder at $1557 \mathrm{~cm}^{-1}$. Bands at 1408, 1374, 1348, 1295, 1252 can be assigned to $\mathrm{N}-\mathrm{H}$ and $\mathrm{C}-\mathrm{H}$ bending and $\mathrm{C}-\mathrm{N}$ stretching. Two peaks at $1078 \mathrm{~cm}^{-1}$ and $1033 \mathrm{~cm}^{-1}$ were attributed to $\mathrm{C}-\mathrm{O}-\mathrm{C}$ stretch as previously reported $[27,29]$. Finally, absorptions at $944 \mathrm{~cm}^{-1}$ and $841 \mathrm{~cm}^{-1}$ were assigned to the pyranose ring. 
(a)

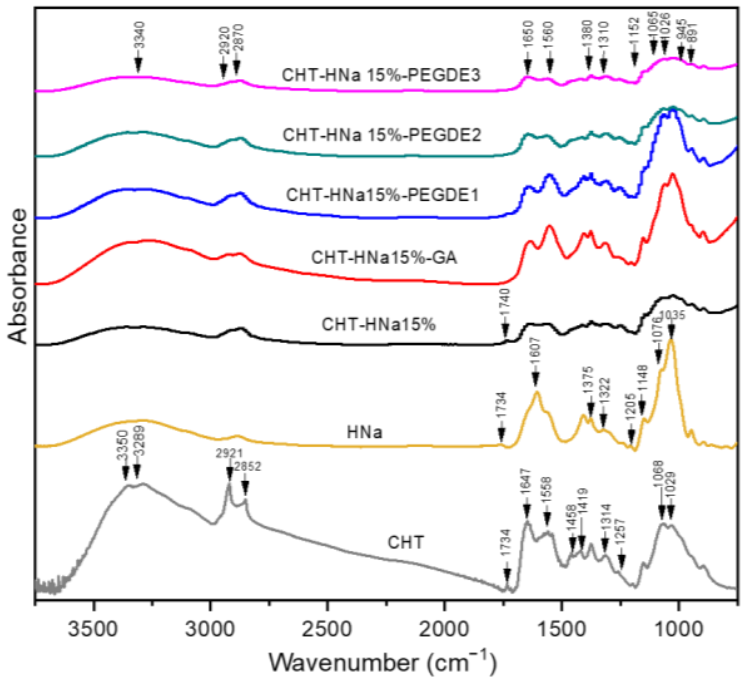

(b)

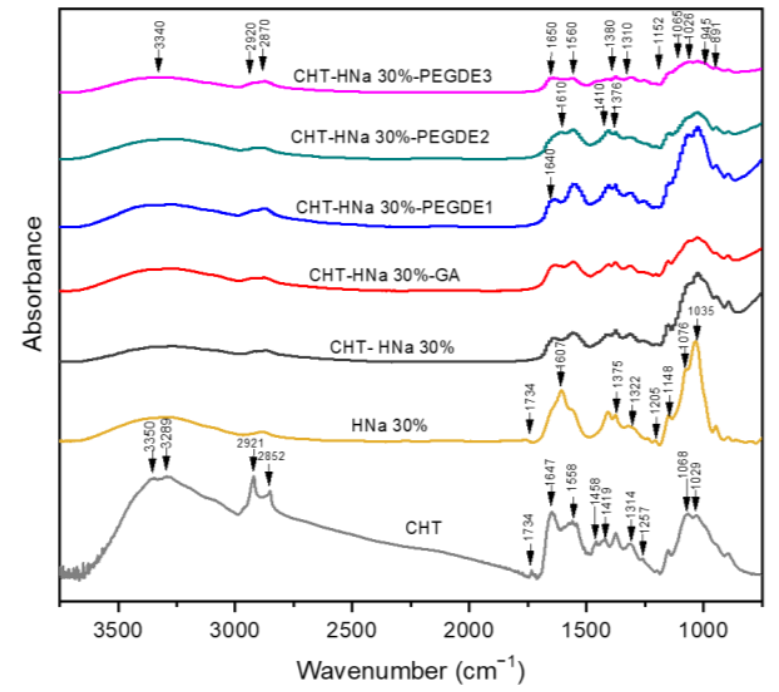

Figure 1. FTIR spectra of PEGDE crosslinked CHT films. HNa 15\% (a) and HNa 30\% (b).

Chitosan and hyaluronic acid are polysaccharides, so both spectra were similar, however when blended might exhibit some differences. The cationic nature of chitosan allows it to interact with negatively charged polymers to form a polyelectrolytic complex (PEC) through ionic bonds. Ionic interactions between chitosan and hyaluronic acid can occur between the amine groups of chitosan and the carboxyl groups of hyaluronic acid.

As expected, when the amount of $\mathrm{HNa}$ increased in the uncrosslinked blend, peaks from $\mathrm{HNa}$ tend to be more evident. For instance, a single $3300 \mathrm{~cm}^{-1}$ band was observed for $\mathrm{NH}$ and $\mathrm{OH}$ stretching absorptions but the bands at 2870 (CH stretching), 1552 (amide II), and $1370 \mathrm{~cm}^{-1}$ increased in agreement with previous works [30]. The FTIR spectra of uncrosslinked $\mathrm{CHT} / \mathrm{HNa} 15 \%$ (Figure 1a) films showed a small band, which can be related to the carboxylate of $\mathrm{HNa}$ located at $1740 \mathrm{~cm}^{-1}$ but it was not observed in CHT/HNa $30 \%$.

The infrared spectra of the CHT/HNa/PEGDE crosslinked films are depicted in Figure 1a,b. When the CHT/HNa was crosslinked with PEGDE a low concentration it showed a single broad band peaking at $3340 \mathrm{~cm}^{-1}$. As HNa increased the band at $2871 \mathrm{~cm}^{-1}$ increased while the absorption at $2919 \mathrm{~cm}^{-1}$ was reduced. Amide I appeared at $1617 \mathrm{~cm}^{-1}$, i.e., between CHT and HNa while Amide II was displaced to $1570 \mathrm{~cm}^{-1}$. Finally, the band at $1375 \mathrm{~cm}^{-1}$ increased as HNa increased.

The main effect of crosslinking with PEGDE was two-fold. First, at both HNa concentrations, Amide II was reduced whereas Amide I increased. Bands located at $1552 \mathrm{~cm}^{-1}$ for PEGDE2 and PEGDE3 crosslinked samples can also be assigned to the deformation vibration of the amine. Therefore, the decrease in the intensity of this band, when the concentration of PEGDE increases, occurs since the epoxy groups of PEGDE react with the amino groups of chitosan and with the carboxyl groups of HNa molecules, decreasing the concentration of amino groups. The second effect of PEGDE was to increase the absorption at $1370 \mathrm{~cm}^{-1}$ suggesting an increase in $\mathrm{CH}_{2}$ groups from PEGDE.

Hwang et al. [31] analyzed the FTIR spectrum of a matrix of HA crosslinked with PEGDE. They indicated that the epoxy group of PEGDE can react with the groups - $\mathrm{COOH}$ $\left(1035 \mathrm{~cm}^{-1}\right)$ and $-\mathrm{OH}\left(3200-3600 \mathrm{~cm}^{-1}\right)$ in HA to form ester and ether linkages after reacting with PEGDE. However, neither their study nor ours, representative bands of ester bond formation $\left(1730 \mathrm{~cm}^{-1}\right)$ were observed indicating that the ratio of ester bond formation is quite low. However, it was reported that the crosslinking of HNa and PEGDE is mainly based on the formation of ether bonds between the hydroxyl groups of $\mathrm{AH}$ and the epoxy groups of PEGDE suggesting the formation of an interpenetrated network [31].

Figure $1 \mathrm{a}, \mathrm{b}$ also shows the infrared spectra of the CHT/HNa/GA crosslinked films. When this crosslinking agent was present it was expected that $\mathrm{NH}$ and $\mathrm{OH}$ groups to 
be reduced or broaden, limiting the formation of a complex. The hydroxyl groups of hyaluronic acid can be crosslinked with the aldehyde groups of glutaraldehyde through an acetalization reaction while imide formation is expected for the case of GA reacting with primary amines from CHT. In this regard, Kutlusoy et al. [16] found broad bands at $3262 \mathrm{~cm}^{-1}$ and $3247 \mathrm{~cm}^{-1}$, attributed to hydroxyl groups being this broadening related to their chemical reaction, which was proved also by the $1639 \mathrm{~cm}^{-1}$ imide formation. In addition, a shift from the band at 1417 to $1405 \mathrm{~cm}^{-1}$ and changes at $1375 \mathrm{~cm}^{-1}\left(\mathrm{CH}_{2}\right)$ during GA crosslinking were also observed. In our study, samples crosslinked with GA, the band located at $1630 \mathrm{~cm}^{-1}$ was observed with less intensity in comparison to the band at $1550 \mathrm{~cm}^{-1}$.

\subsubsection{Raman Spectroscopy}

Figure 2 shows Raman spectra of chitosan mixed with $15 \%$ and $30 \%$ of $\mathrm{HNa}$, crosslinked with either (GA) or crosslinked PEDGE. Pristine chitosan is reported to exhibit intense peaks at 2924 and 2885 for $\mathrm{C}-\mathrm{H}$ stretching vibrations; medium intensity peaks at 1419 , 1376 , shoulder at $1340 \mathrm{~cm}^{-1}$ for C-H bending vibrations, 1116 and $1094 \mathrm{~cm}^{-1}$ and 925 and $898 \mathrm{~cm}^{-1}$ for the pyranose ring. Finally, small intensity peaks at $1666,1634,1535, \mathrm{~cm}^{-1}$ for amide I and II, respectively [32,33]. We observed peaks at 2930, 1604, 1411, 1382, 1115, 1093,925 , and $898 \mathrm{~cm}^{-1}$ absorptions (see supplementary information, S2) in agreement with previous studies.

(a)

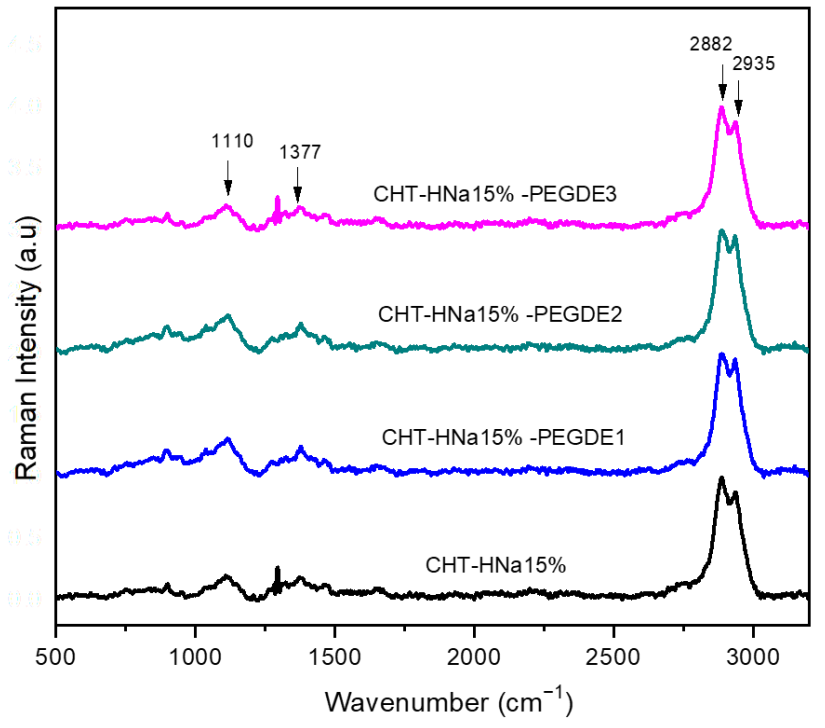

(b)

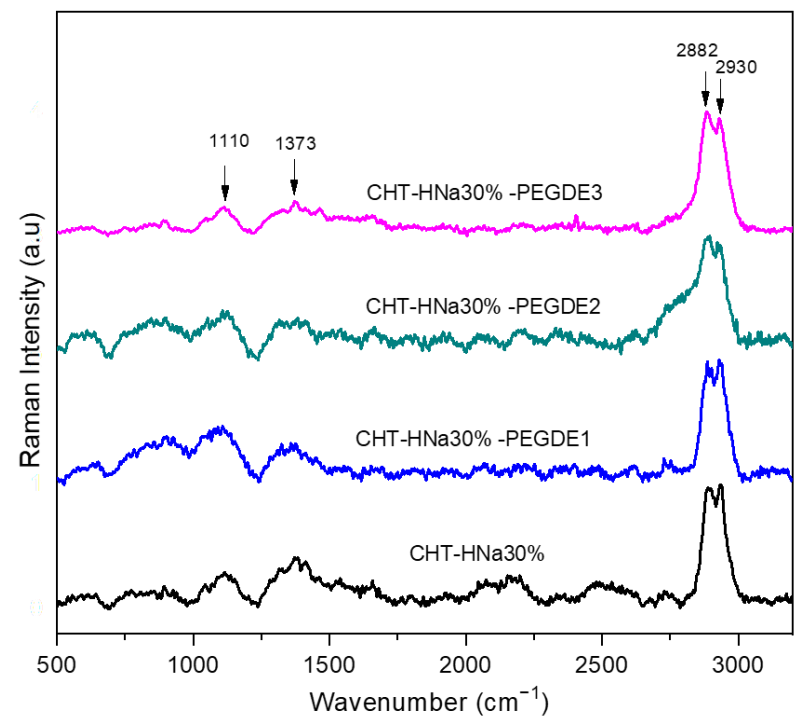

Figure 2. (a) Raman spectra of PEGDE crosslinked CHT films. HNa 15\% (a) and HNa 30\% (b).

On the other hand, pristine HNa spectra (see supplementary information, S3) showed five subregions of different intensities $(\mathrm{i}=$ intense, $\mathrm{m}=$ medium and $\mathrm{s}=$ small: (1) $\mathrm{C}-\mathrm{H}$ stretching vibrations $\left(2940 \mathrm{i}, 2934 \mathrm{i}\right.$ and $\left.2900 \mathrm{~s} \mathrm{~cm}^{-1}\right)$, (2) stretching vibrations of carbonyl compounds $\left(1645 \mathrm{~s} \mathrm{~cm}^{-1}\right)$, (3) deformation modes of $\mathrm{C}-\mathrm{H}_{2}$ y C-OH $(1410 \mathrm{~s}, 1360 \mathrm{~m}, 1329 \mathrm{~m}$, and $\left.1305 \mathrm{~m} \mathrm{~cm}^{-1}\right)$, (4) $\mathrm{C}-\mathrm{O}$ and $\mathrm{C}-\mathrm{C}$ stretching vibrations $\left(1130 \mathrm{i}, 1086 \mathrm{~m}, 1048 \mathrm{~m} \mathrm{~cm}^{-1}\right.$ ) and, (5) complex skeletal vibrations out of plane (941s and $893 \mathrm{~s} \mathrm{~cm}^{-1}$ ) in agreement with previous studies $[32,34,35]$. However, as our study was on solid hyaluronate films and not in solution, the presence of shoulder at 1630 and $1600 \mathrm{~cm}^{-1}$ assigned to carboxylate were not observed. Despite this, a very low intensity peak at $1552 \mathrm{~cm}^{-1}$ was observed and can be assigned to amide II in $\mathrm{HNa}$.

When these two polysaccharides are blended, the C-H vibration at $2935-2930 \mathrm{~cm}^{-1}$ increased as $\mathrm{HNa}$ concentration increased with respect to the vibration at $2887 \mathrm{~cm}^{-1}$. The small intensity absorption at $1657 \mathrm{~cm}^{-1}$ located between the ones of the pristine polymers 
suggests a shift for amide I band. The band a $1538 \mathrm{~cm}^{-1}$ (amide II) also shifted, which was more evident with increasing amounts of HNa. However, vibrations at $1371 \mathrm{~cm}^{-1}$ and $1115 \mathrm{~cm}^{-1}$ remained unchanged.

The main signals observed in the $\mathrm{CHT} / \mathrm{HNa}$ /PEGDE films were related to the bands at $2933 \mathrm{~cm}^{-1}$ and $2886 \mathrm{~cm}^{-1}$ where the latter increased with PEGDE concentration. Similarly, the band at $1461 \mathrm{~cm}^{-1}$ increased and probably corresponded to pristine PEGDE but being displaced. Vibrations at $1376 \mathrm{~cm}^{-1}$ and $1113 \mathrm{~cm}^{-1}$ and $890 \mathrm{~cm}^{-1}$ remained with medium intensity. Increases in intensity were expected for $1470 \mathrm{~cm}^{-1}, 1256 \mathrm{~cm}^{-1}, 1134 \mathrm{~cm}^{-1}$, and $841 \mathrm{~cm}^{-1}$ as PEGDE increased but this was not clearly observed.

\subsubsection{Thermogravimetric Analysis (TGA)}

Figure 3 shows TGA and DTGA thermograms of GA crosslinked and PEGDE crosslinked chitosan/HNa films at 15\% (Figure 3a,c) and 30\% (Figure 3b,d). It was observed that the degradation profile for all films presented two stages. The first stage $\left(\mathrm{T}_{\mathrm{d} 1}\right)$ was located between $56-70{ }^{\circ} \mathrm{C}$ for CHT-HNa $15 \%$ films and $60-63{ }^{\circ} \mathrm{C}$ for CHT-HNa $30 \%$ films. The second stage $\left(\mathrm{T}_{\mathrm{d} 2}\right)$ was detected at $285-300{ }^{\circ} \mathrm{C}$ for $\mathrm{CHT}-\mathrm{HNa} 15 \%$ films and $272-300{ }^{\circ} \mathrm{C}$ for CHT-HNa $30 \%$ films. The first weight loss for all films was between $7-12 \%$. This change was related to the loss of water and residual acid by evaporation, which means that the water is physically retained by weak hydrogen bonds on chitosan surface. The second weight loss was located between $52-66 \%$. This loss of mass corresponded to the thermal degradation of chitosan, and simultaneous removal of volatile products. The maximum rate of thermal decomposition of the pristine chitosan $\left(\mathrm{T}_{\mathrm{d} 2}\right)$ took place at $297^{\circ} \mathrm{C}$, while HNa decomposed at $222^{\circ} \mathrm{C}$ although Réef et al. reported that degradation of hyaluronate occurred at $210^{\circ} \mathrm{C}[36]$.

When $\mathrm{HNa}$ at $15 \%$ was added to $\mathrm{CHT}$ an increase in $\mathrm{T}_{\mathrm{d} 2}$ temperature was also observed. This increase was from $297^{\circ} \mathrm{C}$ for pure chitosan to $386^{\circ} \mathrm{C}$ for chitosan with $15 \%$ $\mathrm{HNa}$. For the uncrosslinked blend with $30 \% \mathrm{HNa}$ films $\mathrm{T}_{\mathrm{d} 2}$ remained unchanged $\left(292^{\circ} \mathrm{C}\right)$. This outcome indicates that by increasing the $\mathrm{HNa}$ concentration does not decrease the thermal stability of the material although $\mathrm{T}_{\mathrm{d} 2}$ of pristine $\mathrm{HNa}$ was lower than $\mathrm{CHT}$. In PEGDE1 and PEGDE2 crosslinked films with $15 \%$ of $\mathrm{HNa}$, a slight increase in $\mathrm{T}_{\mathrm{d} 1}$ was observed (Table 2), i.e., from $65{ }^{\circ} \mathrm{C}$ (pure chitosan) to $70{ }^{\circ} \mathrm{C}$ (chitosan with $15 \%$ of $\mathrm{HNa}$ ) but for PEGDE 3 no change was observed. In contrast, $\mathrm{T}_{\mathrm{d} 2}$, increased for all PEGDE crosslinked films (Table 2). When HNa was added at 30\%, PEGDE crosslinked films, $\mathrm{T}_{\mathrm{d} 1}$ and $\mathrm{T}_{\mathrm{d} 2}$ were slightly reduced except for PGDE3, which remined the same in agreement with Kutlusoy et al. [16] who reported that as the amount of hyaluronic acid increases in CHT cryogels, the thermal stability and the amount of char decrease. In comparison with pristine CHT films, GA crosslinked films exhibited higher $\mathrm{T}_{\mathrm{d} 2}$ at $15 \%$ of $\mathrm{HNa}$ but lower $\mathrm{T}_{\mathrm{d} 2}$ when used at $30 \%$. Table 2 summarizes the thermal properties of these films.

The higher thermal stability of CHT/HNa blends was achieved with $15 \%$ without crosslinking agent $\left(386^{\circ} \mathrm{C}\right)$. The higher thermal stability of CHT/HNa/PEGDE crosslinked films was achieved with low PEGDE concentrations and $15 \%$ of sodium hyaluronate (344-348 ${ }^{\circ} \mathrm{C}$ ). In addition, the one with the highest thermal stability was the chitosan film crosslinked with GA $\left(354{ }^{\circ} \mathrm{C}\right)$. Presumably, this outcome was due to the double crosslinking with GA, i.e., the formation of interpenetrated network as well as to the secondary interactions between the chitosan and hyaluronic acid chains [16].

The temperature of $50 \%$ of loss of mass (Table 1 ) of pristine CHT decreased almost $50{ }^{\circ} \mathrm{C}$ when $\mathrm{CHT}$ film was mixed with $15 \%$ of $\mathrm{HNa}$ and crosslinked with PEGDE but slightly decreased when $30 \%$ was added. This temperature slightly increased for GA crosslinked samples with $30 \%$ of $\mathrm{HNa}$. 
(a)

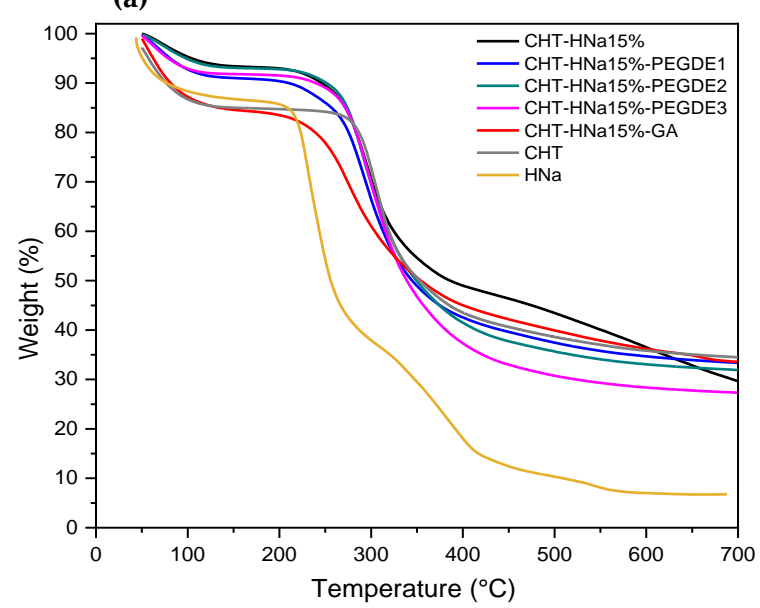

(c)



(b)

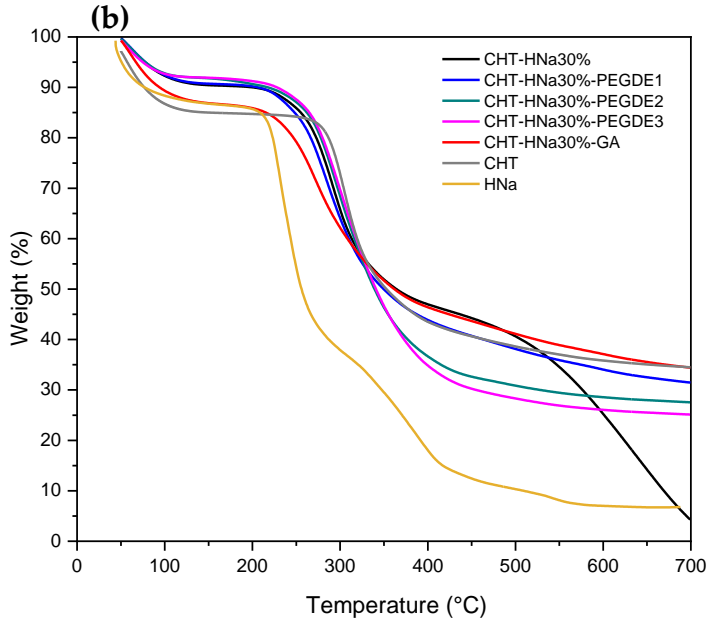

(d)



Figure 3. TGA and DTGA thermograms of GA crosslinked and PEGDE crosslinked chitosan/HNa films. TGA (a,b) and DTGA (c,d). HNa content of $15 \%(\mathbf{a}-\mathbf{c})$, HNa content $30 \%(\mathbf{b}-\mathbf{d})$.

Table 2. Decomposition temperatures and weight loss of $\mathrm{CHT}$ films, $\mathrm{CHT} / \mathrm{HNa}$ at $15 \%$ and $30 \%$ films crosslinked with GA and PEGDE.

\begin{tabular}{|c|c|c|c|c|c|c|}
\hline Films & \multicolumn{4}{|c|}{$\mathrm{T}_{\mathrm{d}}\left({ }^{\circ} \mathrm{C}\right)$} & \multicolumn{2}{|c|}{$T\left({ }^{\circ} \mathrm{C}\right)$ at $50 \%$ of Weight Loss } \\
\hline \multirow[t]{3}{*}{$\mathrm{CHT}$} & 65 & 297 & & & \multicolumn{2}{|c|}{351} \\
\hline & \multicolumn{2}{|c|}{$\mathrm{HNa} 15 \%$} & \multicolumn{2}{|c|}{$\mathrm{HNa} 30 \%$} & $\mathrm{HNa} 15 \%$ & $\mathrm{HNa} 30 \%$ \\
\hline & $\mathrm{T}_{\mathrm{d} 1}$ & $\mathrm{~T}_{\mathrm{d} 2}$ & $\mathrm{~T}_{\mathrm{d} 1}$ & $\mathrm{~T}_{\mathrm{d} 2}$ & & \\
\hline CHT-HA & 68 & 386 & 60 & 292 & 295 & 360 \\
\hline CHT-HA-PEGDE 1 & 70 & 344 & 63 & 285 & 295 & 349 \\
\hline CHT-HA-PEGDE 2 & 70 & 348 & 63 & 295 & 290 & 340 \\
\hline CHT-HA-PEGDE 3 & 64 & 338 & 62 & 300 & 298 & 340 \\
\hline CHT-HA-GA & 56 & 354 & 61 & 272 & 276 & 358 \\
\hline
\end{tabular}

\subsubsection{X-ray Diffraction (XRD)}

Figure 4 shows the diffractograms of the samples of pristine chitosan, pristine $\mathrm{HNa}$, and chitosan mixed with $\mathrm{HNa}$ at $15 \%$ (Figure $4 \mathrm{a}$ ) and $30 \%$ (Figure $4 \mathrm{~b}$ ) crosslinked with GA and PEGDE at different concentrations. The diffraction pattern of pristine CHT showed the two characteristic sharp peaks at $2 \theta=9.5^{\circ}$ and $2 \theta=20^{\circ}$, which are typical of the hydrated conformation of chitosan [37]. In contrast, completely amorphous sodium hyaluronate was obtained after film preparation. 
(a)

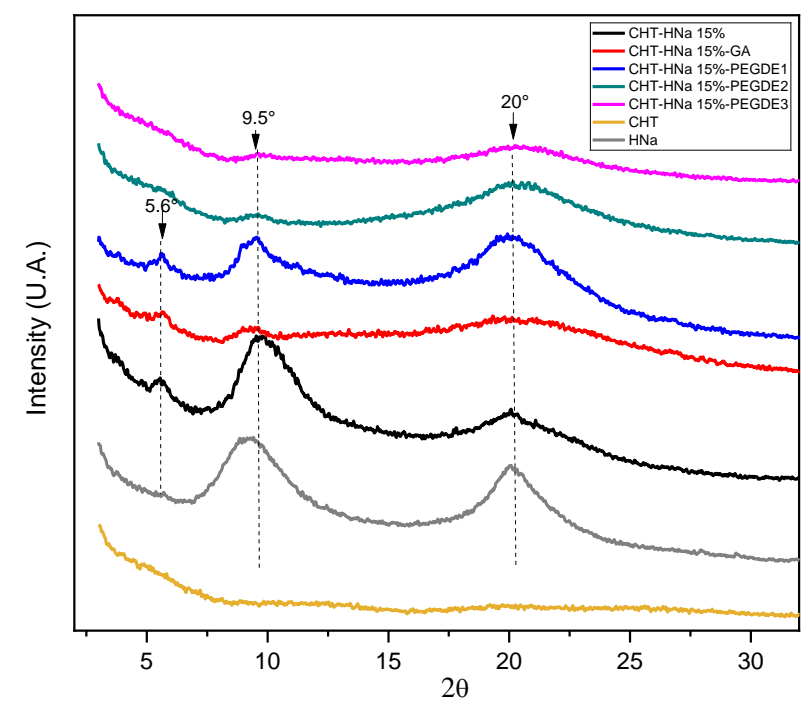

(b)

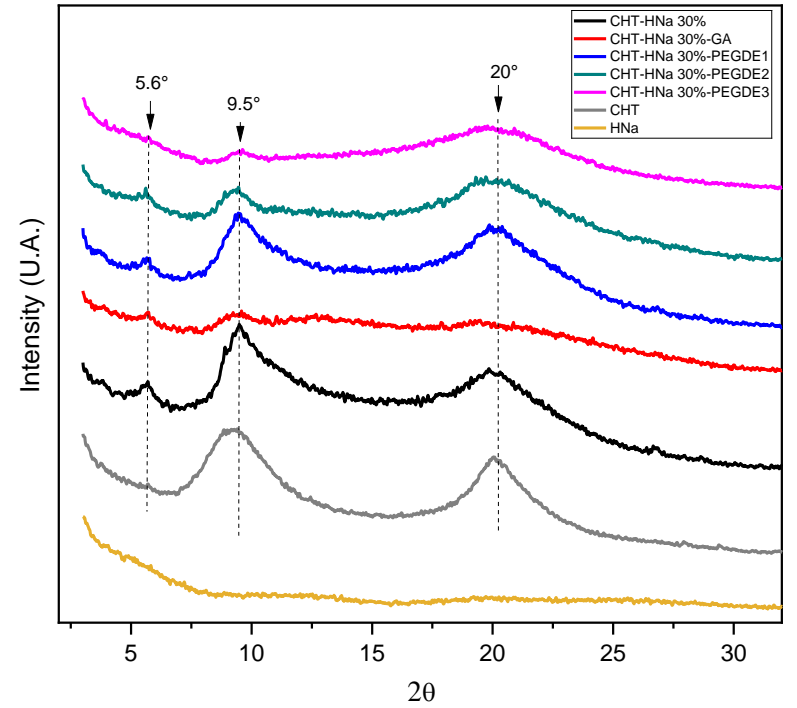

Figure 4. XRD pattern of GA crosslinked and PEGDE crosslinked chitosan/HNa films. HNa content of $15 \%$ (a), HNa content $30 \%(\mathbf{b})$.

Regarding X-ray diffraction of hyaluronic acid, Meyer suggested that high molecular weight hyaluronates may contain some non-glycosidic bonds that act as branch points. The removal of these branches by acid treatment can cause depolymerization and, at the same time, can allow crystalline organization [38]. Sheehan et al. reported that the conformation of hyaluronate chains in the solid state is dependent on the nature of the cations that are presented, the $\mathrm{pH}$, and the temperature at which the crystallization is carried out, but not on the ionic strength of the solution from which films are molded. Depending on the cation, successful crystallization of these conformations requires the presence of various water molecules [39]. Hyaluronates peaks at approximately $2 \theta=26^{\circ}$ and $32^{\circ}$ have been reported, but these were not observed in our samples [40]. In contrast, X-ray diffraction studies have shown that hyaluronic acid films or fibers are amorphous in nature [41]. CHT/HNa uncrosslinked blends showed an additional peak at $2 \theta=5^{\circ}$, similar to those reported by Nath et al. [42] and by us [28]. They pointed out that this outcome can be attributed to the formation of more ordered complexes, inducing a change in crystallinity.

Films crosslinked with PEGDE at different concentrations exhibited peaks like those of films without crosslinking but with a peak reduction in intensity as PEGDE concentration increased. There were no obvious changes in the diffractograms at both $\mathrm{HNa}$ contents but in the $30 \% \mathrm{HNa}$ films, the intensity of the peak at $2 \theta=20^{\circ}$ slightly increases in the PEGDE3 crosslinked samples. Likewise, GA crosslinked samples were amorphous and did not show different diffraction patters for both $\mathrm{HNa}$ concentrations.

The crystallinity of the chitosan samples with sodium hyaluronate decreased in the presence of the HNa and when the sample was crosslinked. Hence, one way to modify crystallinity without resorting to heat treatment or crosslinking is by adding a second polymer phase. For a more accurate comparison, Table 3 summarizes the results obtained from the calculation of the crystallinity index (CrI) of each of the films. 
Table 3. Percentage of the crystallinity of the chitosan/HNa films without crosslinker and with crosslinker of GA and PEGDE.

\begin{tabular}{ccc}
\hline & \multicolumn{2}{c}{ CrI\% } \\
\hline Films & & \\
\hline CHT & & 64.17 \\
\hline CHT /HNa & $15 \%$ & $30 \%$ \\
\hline CHT-HNA-PEGDE 1 & 60.76 & 46.05 \\
\hline CHT-HNa-PEGDE 2 & 42.12 & 43.24 \\
\hline CHT-HNa-PEGDE 3 & 31.56 & 46.66 \\
\hline CHT-HNa-GA & 19.5 & 27.86 \\
\hline
\end{tabular}

\subsection{Surface Properties of Crosslinked CHT}

\subsubsection{X-ray Photoelectron Spectroscopy (XPS)}

XPS survey spectra of chitosan films with $15 \%$ and $30 \%$ of $\mathrm{HNa}$ are shown in Figure 5. Because hyaluronic acid and chitosan are polysaccharides with a similar molecular structure, C1s, N1s, and O1s, were detected. The presence of Ca was also recorded, which may come from the exoskeleton of the source, and Si considered as contaminant (Table 4). The only difference between $\mathrm{CHT}$ and $\mathrm{HNa}$ lies in the carboxyl group in $\mathrm{HNa}$ and the amino groups in chitosan and therefore Na1s was also detected for the corresponding salt [30]. When HNa was added to CHT there was an increase in the concentration of $\mathrm{Na}$ and increased from 0.27 at.\% for films with $15 \% \mathrm{HNa}$ to 1.26 at. $\%$ for films with $30 \%$ of $\mathrm{HNa}$. Although it was expected an increase in oxygen with $\mathrm{HNa}$ addition due to the COOgroups, this was only observed for $\mathrm{CHT} / \mathrm{HNa} 15 \%$ films and a reduction for $\mathrm{CHT} / \mathrm{HNa}$ $30 \%$ uncrosslinked films. The latter behavior implied that oxygen is no longer in the surface but forming a complex in the bulk. This was also corroborated by the nitrogen content reduction.


Figure 5. XPS survey spectra of GA crosslinked and PEGDE crosslinked chitosan/HNa films. HNa content of $15 \%$ (a), HNa content $30 \%$ (b). 
Table 4. XPS elemental composition of chitosan/HNa films crosslinked with GA and PEGDE.

\begin{tabular}{cccccccc}
\hline & $\mathbf{H N a}$ & $\mathbf{\% C}$ & $\mathbf{\% O}$ & $\mathbf{\% N}$ & $\mathbf{\% N a}$ & $\mathbf{\% S i}$ & $\mathbf{\%} \mathbf{C a}$ \\
\hline CHT & & $70.13 \pm 1$ & $22.23 \pm 2$ & $4.64 \pm 0.6$ & - & $1.27 \pm 1$ & $1.74 \pm 0.7$ \\
CHT/HNa & $15 \%$ & $69.14 \pm 3$ & $24.67 \pm 2$ & $4.79 \pm 2$ & $0.27 \pm 0.2$ & $0.88 \pm 0.8$ & $0.25 \pm 0.1$ \\
& $30 \%$ & $76.6 \pm 5$ & $18.4 \pm 1$ & $3 \pm 0.2$ & $1.26 \pm 0.5$ & $0.74 \pm 0.3$ & - \\
CHT-PEGDE1 & $15 \%$ & $76.2 \pm 2$ & $20.56 \pm 1$ & $2.72 \pm 0.9$ & $0.52 \pm 0.4$ & - & - \\
& $30 \%$ & $74.93 \pm 4$ & $20.11 \pm 2$ & $3.21 \pm 0.8$ & $0.73 \pm 0.1$ & $1.02 \pm 0.9$ & - \\
CHT-PEGDE2 & $15 \%$ & $69.3 \pm 1$ & $25.67 \pm 3$ & $3.7 \pm 0.9$ & $0.8 \pm 0.2$ & - & $0.55 \pm 0.2$ \\
& $30 \%$ & $75.22 \pm 2$ & $22 \pm 1$ & $1.85 \pm 1$ & $0.93 \pm 0.3$ & - & - \\
CHT-PEGDE3 & $15 \%$ & $66 \pm 5$ & $27.8 \pm 3$ & $4.10 \pm 1$ & $0.83 \pm 0.2$ & $1.27 \pm 1$ & - \\
& $30 \%$ & $74 \pm 3$ & $20 \pm 2$ & $3.9 \pm 1$ & $0.96 \pm 0.1$ & $0.79 \pm 0.3$ & $0.35 \pm 0.5$ \\
CHT-GA & $15 \%$ & $75.5 \pm 1$ & $21.2 \pm 2$ & $2.62 \pm 0.8$ & $0.68 \pm 0.2$ & - & - \\
& $30 \%$ & $75 \pm 2$ & $22 \pm 3$ & $3 \pm 1$ & - & - & - \\
\hline
\end{tabular}

PEGDE crosslinked films showed an increased in oxygen content as the crosslinker agent increased i.e., from 24 at. \% (CHT/HNa 15\%) up to 27 at.\% (CHT/HNa 15\% PEGDE3 crosslinked). A clearer behavior was observed for $\mathrm{CHT} / \mathrm{HNa} 30 \%$ PEGDE crosslinked samples as it varied from 18 at. $\%$ to 22 at. $\%$.

GA crosslinked sample showed a reduction in oxygen and nitrogen content for $15 \%$ $\mathrm{HNa}$ and an increase in carbon content with respect to the CHT/HNa uncrosslinked sample. However only an increase in oxygen content was detected for 30\% $\mathrm{HNa}$ films. However, the contained nitrogen decreased from 5\% to 3\% (Supplementary data S4 showed the corresponding XPS scans for $\mathrm{C}, \mathrm{N}$ and $\mathrm{O}$ ).

\subsubsection{Surface Topography by AFM}

Atomic force microscopy was used to assess the surface topography of sodium hyaluronate chitosan films crosslinked with glutaraldehyde and PEGDE at different concentrations. Figure 6 shows the 3D topography while Table 5 presents the corresponding roughness. The addition of $15 \% \mathrm{HNa}$ to uncrosslinked $\mathrm{CHT}$ increased surface roughness $(64.7 \mathrm{~nm})$ but reduce it $(31.7 \mathrm{~nm})$ when $30 \% \mathrm{HNa}$ was used. Crosslinking with PEGDE or GA reduced surface roughness for $\mathrm{CHT} / \mathrm{HNa} 15 \%$ but tend to increase it for $\mathrm{CHT} / \mathrm{HNa} 30 \%$.

(a)



(f)



(b)

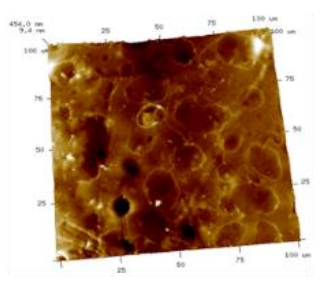

(g)

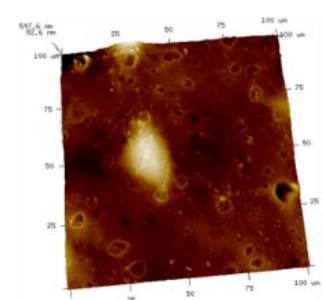

(c)

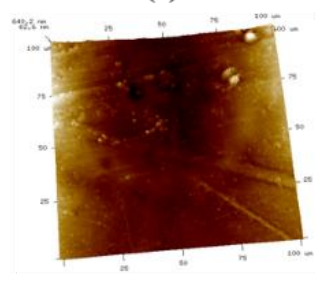

(h)

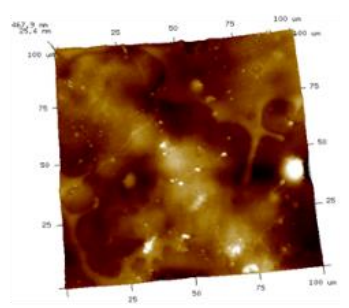

(d)

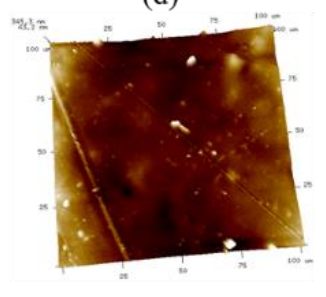

(i)

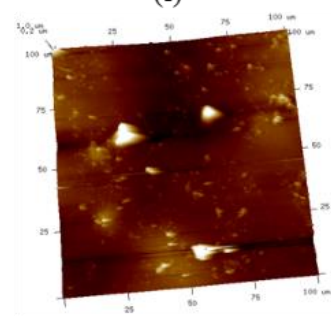

(e)

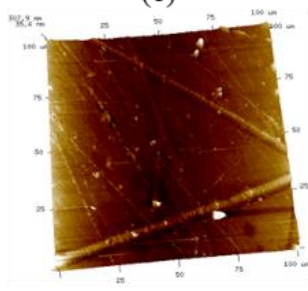

(j)

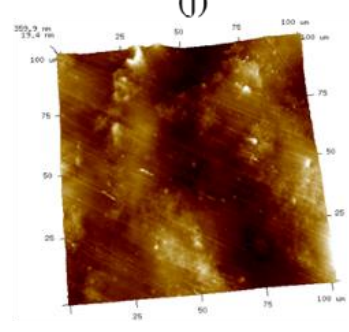

Figure 6. 3D topography of GA crosslinked and PEGDE crosslinked chitosan/HNa films. HNa 15\% (Top, a-e) and HNa 30\% (bottom, f-j); (a) CHT/HNa15, (b) CHT/HNa15\%/PEDGE1, (c) CHT/HNa15\%/PEDGE2, (d) CHT/HNa15\%/PEDGE3, (e) $\mathrm{CHT} / \mathrm{HNa} 15 \% / \mathrm{GA}$, (f) CHT/HNa30\%, (g) CHT/HNa30\%/PEDGE1, (h) CHT/HNa30\%/PEDGE2, (i) CHT/HNa30\%/ PEDGE3, (j) $\mathrm{CHT} / \mathrm{HNa} 30 \% / \mathrm{GA}$. 
Table 5. Roughness and contact angle of GA crosslinked and PEGDE crosslinked chitosan/HNa films.

\begin{tabular}{ccccccc}
\hline & \multicolumn{3}{c}{ Ra (nm) } & \multicolumn{3}{c}{ Contact Angle ( ${ }^{\circ}$ ) } \\
\hline Films & \multicolumn{2}{c}{$45.8 \pm 5$} & $\mathbf{H}_{\mathbf{2}} \mathbf{O}$ & DMEM & $\mathbf{H}_{\mathbf{2}} \mathbf{O}$ & DMEM \\
\hline CHT & \multicolumn{2}{c}{$62.9 \pm 3$} & $72 \pm 4$ \\
\hline CHT-HNa & $64.7+7.3$ & $31.7 \pm 2.6$ & $73^{\circ}$ & $74^{\circ}$ & $74^{\circ}$ & $66^{\circ}$ \\
\hline CHT-HNa-PEGDE1 & $85.3 \pm 9.6$ & $106.2 \pm 8.9$ & $66^{\circ}$ & $52^{\circ}$ & $52^{\circ}$ & $55^{\circ}$ \\
\hline CHT-HNa-PEGDE2 & $56.8 \pm 5.8$ & $87.8 \pm 6.9$ & $60^{\circ}$ & $56^{\circ}$ & $56^{\circ}$ & $47^{\circ}$ \\
\hline CHT-HNa-PEGDE3 & $61.2 \pm 5.2$ & $134.3 \pm 14.2$ & $51^{\circ}$ & $54^{\circ}$ & $54^{\circ}$ & $44^{\circ}$ \\
\hline CHT-HNa-GA & $44.6+5.9$ & $52.6 \pm 7.2$ & $68^{\circ}$ & $42^{\circ}$ & $42^{\circ}$ & $18^{\circ}$ \\
\hline
\end{tabular}

Assessment of topography by AFM is an important parameter, since it is known that cells tend to adhere to rougher surfaces features at the micro and nanoscale [19]. Lewandowska pointed out that the repulsion forces and/or the electrostatic interactions between the components of this type of mixtures can lead to an increase in the size of the microdomain. These interactions play an important role in the structure and properties of binary and ternary polymer blends. The biopolymers used, that is, hyaluronic acid and chitosan are polyelectrolytes, in which the properties are strongly associated with the electrostatic interactions that determine the shape of the macromolecule. In the aqueous solution of a polyelectrolyte, the macromolecules are stretched due to electrostatic repulsive forces between charges on the functional groups. Therefore, in these mixtures, interactions by hydrogen bonds and repulsive forces mainly predominate. These factors can lead to decrease surface homogeneity and increased roughness as in these compositions [43]. Furthermore, it is possible that phase separation take place due to the slow acetic acid evaporation. This was only perceived by AFM in CHT-HNa films crosslinked as some $\mathrm{HNa}$ islands can be observed in CHT/HNa 15\% PEGDE1 films.

\subsubsection{Measurement of Contact Angle}

The contact angle $(\theta c)$ formed by a drop of water on a flat solid surface is a macroscopic manifestation of surface-water interactions at the molecular level and is used to characterize surface wetting phenomena [44]. The wettability of a surface is determined by the chemistry of the surface and its topography. For an ideal film surface that is flat, smooth, and chemically homogeneous, the contact angle will decrease as the surface polarity increases.

The contact angle of the surfaces of the crosslinked CHT films with the different content of HNa are shown in Table 5. CHT films showed, in general, water contact angles lower than $72^{\circ}$, which were classified as weakly hydrophilic [37]. The incorporation of $\mathrm{HNa}$ and PEGDE reduced the contact angles in water and culture media in agreement with current literature [30]. This may be due to a greater amount of oxygen, given by PEGDE, on the surface of the films. In addition, this effect can also be explained by the fact that chitosan films with hyaluronate possess a complex chemical structure with amide, amine, and carboxyl groups, so the contact angle on a CHT-HNa surface must reflect the presence of these groups. Perhaps, this integration results in increased polarity at the CHT-AH film surface, reflecting as a lower contact angle. When DMEM was used as the sessile drop the contact angle was, in general, lower suggesting also possible interaction of proteins with this surface.

For GA crosslinked CHT/HNa films there was also a reduction in water contact angle which was more marked when $\mathrm{HNa}$ was added at $30 \%$. This implies that GA is a more effective crosslinker for CHT rendering a surface richer in HNa. Improved hydrophilicity when hyaluronate is incorporated into chitosan can have positive effects on cytocompatibility [45].

Muzzio et al. [19], measured contact angle with HEPES buffer and acetate buffer, in chitosan/hyaluronic acid polyelectrolyte multilayers, found that the value of contact angle 
decreases from $30.2^{\circ}$ to $20.6^{\circ}$ after annealing. So, they conclude that PEMs are hydrophilic despite thermal annealing. Romero-Vargas et al. [44] reported that surface functionalization with PEG inhibits the adsorption of biomolecules, a property that is due in part to the ability of PEG to participate in interactions of hydrogen bonds with surrounding water molecules, i.e., hydrophilicity of the surface. PEGDE films have a more hydrophilic active layer reflected by a lower contact angle. Hydrogen bond accepting groups (i.e., $\mathrm{O}$ atoms) in ethylene glycol monomers enhanced the affinity of water for amino-PEGDE surfaces.

\subsection{Cell Viability and Proliferation Studies}

When developing materials for biomedical applications, a very important factor to consider is toxicity and this can be followed by using conventional MTS cytotoxicity tests [46]. Figure 7 shows the MTS cytotoxicity test performed on the chitosan films with $15 \%$ and $30 \%$ of sodium hyaluronate, crosslinked with glutaraldehyde and with different concentrations of PEGDE.

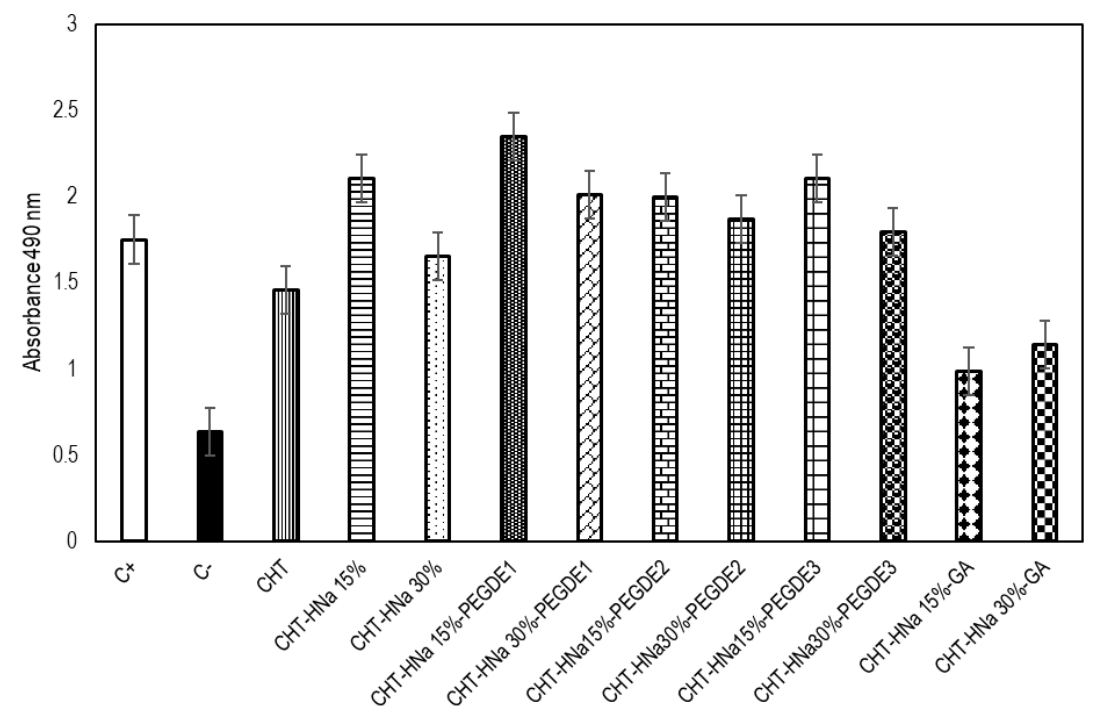

Figure 7. Viability of osteoblast with Chitosan (CHT), Chitosan and $\mathrm{HNa}(\mathrm{CHT} / \mathrm{HNa})$, glutaraldehyde crosslinked chitosan/HNa (CHT-HNa-GA), PEDGE crosslinked chitosan/HNa (CHT-HNaPEDGE) at $15 \%$ and $30 \%$ of $\mathrm{HNa}$.

From Figure 7 it can be clearly seen that the cell viability of the pristine chitosan scaffolds improved with $15 \% \mathrm{HNa}$ but a slight decrease was observed when the concentration of $\mathrm{HNa}$ was increased up to $30 \%$. At low $\mathrm{HNa}$ concentrations it is possible that more amino groups from $\mathrm{CHT}$ are available while at 30\% $\mathrm{HNa}$ cell adhesion is reduced due to complex formation and reduction of free $\mathrm{NH}_{2}$ [47]. This behavior was enhanced when low PEGDE concentrations were used (PEGDE1) suggesting that a more hydrophilic surface improved cell viability. However, the competitive effect between HNa and PEGDE is also clear, i.e., low PEGDE concentrations work better for low HNa concentrations [48].

For GA crosslinked CHT/HNa films viability was lower than PEGDE crosslinked samples. However, when high $\mathrm{HNa}$ concentration were used osteoblast viability increased even when the surface roughness was similar to that of pristine CHT with more available free amino groups.

Kutlusoy et al. reported that the use of low concentrations of glutaraldehyde did not affect cell growth and proliferation. This is consistent with the findings in the present investigation. Despite the fact that osteoblast survival is observed in our samples with GA, they exhibited the lowest values of cell viability for both $\mathrm{HNa}$ concentrations $(15 \%$ and $30 \%)$ [16].

Nath et al. [42] evaluated cell proliferation in chitosan scaffolds with hyaluronic acid. They reported a significant difference in cell behavior on scaffolds and indicated that 
hyaluronic acid improves cell proliferation. Those results coincided with previous studies that suggest that chitosan-hyaluronic acid-based matrices (hydrogels, electrospun fibers) provide a favorable surface for cell adhesion and proliferation.

\section{Cellular Adhesion by Scanning Electron Microscopy (SEM)}

Cellular adhesion was observed by SEM by direct and indirect contact after $48 \mathrm{~h}$ (Figure 8). A better interaction and cellular morphology were observed in direct contact, since the cytoplasmic extensions and the organization of the osteoblasts in the form of clusters were observed.

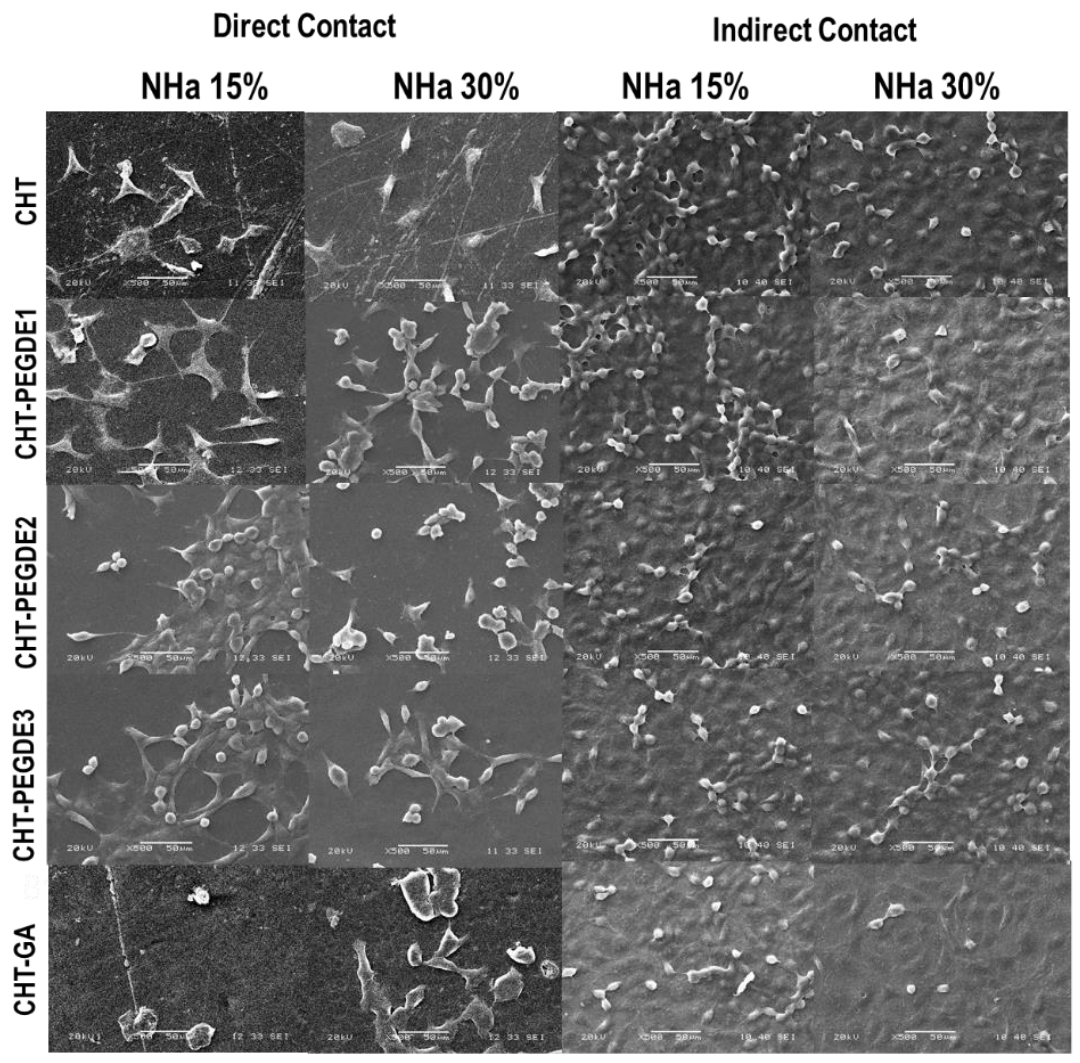

Figure 8. SEM images of osteoblast seeded onto CHT scaffolds on direct and indirect contact.

Chitosan films with $15 \%$ on $\mathrm{HNa}$, showed a better adhesion when they were crosslinked with PEGDE; moreover, a better cell morphology was observed in scaffolds crosslinked with PEGDE 1 (low concentrations). The same effects were observed in scaffolds with $\mathrm{HNa}$ at 30\% with a smaller number of well-shaped cells. Osteoblasts were scarce in CHT/HNa samples crosslinked with glutaraldehyde for both concentrations of HNa. Muzzio et al. [19], reported that CHT/HA polyelectrolites exhibited a significant positive effect on cell adhesion in agreement with our results.

According to Casimiro et al., cells seem to prefer more homogeneous surfaces with smaller pores. We observe this effect in our samples, where all the films have a homogeneous surface [49].

Our results not only showed that osteoblasts optimally adhered to our CHT/HNa samples exhibiting a good viability, but they also showed that osteoblast proliferated considerably in the PEGDE crosslinked scaffolds. Furthermore, osteoblasts aggregated into nodules consisted of large groups of spherical cells at the beginning and then their cytoskeleton is flattened, which would lead to the synthesis and secretion of components of the autologous matrix [28] and, eventually, to bone formation [31]. 


\subsection{Antimicrobial Activity}

Figure 9 shows the inhibitory halo achieved when the bacterial strains are exposed to antibiotics to confirm the effectiveness of the method. In contrast, no inhibitory effect was observed on the studied samples by using Kirby-Bauer method in the presence of Escherichia coli, Enterococcus faecalis and Staphylococcus aureus.



Figure 9. Inhibitory halo of antibiotics in contact with different strain ((A) E. faecalis, (B) E. coli and (C) S. aureus) and chitosan/HNa discs in contact with: E. faecalis (D), E. coli (E-I) and S. aureus (J-L). 
Many studies suggest that the antibiofilm property of chitosan is attributed to the polycationic nature of its $\mathrm{N}-\mathrm{H} 2$ groups of the $\mathrm{N}$-acetylglucosamine units. [20,50,51]. However, there are studies that indicate that the antibacterial activity of chitosan can be influenced by molecular weight, DDA and environmental conditions (e.g., the $\mathrm{pH}$ ), type of derivative, solvent composition [50,52], bacterial strain, culture media, temperature, ionic strength, metal ions, EDTA, and organic matter among others [51]. It is worth mentioning that all our films were at a neutral $\mathrm{pH}(7+0.5)$ and it is acknowledged that the antimicrobial and antibiofilm properties of chitosan and its derivatives are usually functional under the acidic condition [20], i.e., reducing its antimicrobial activity at $\mathrm{pH} 7.0$ [51].

Xing et al. indicate that Oleoyl-chitosan nanoparticle were antibacterial against E. coli and $S$. aureus by damaging the structures of the cell membrane and the alleged binding to extracellular targets such as phosphate groups or intracellular targets such as DNA.

The hydrophilicity of the films, measured by contact angle, would provide a high affinity for water molecules, which would give our samples anti-fouling properties, as Muzzio et al. pointed out [19]. However, in contrast to the results of Muzzio et al., in our samples, no decrease in bacterial adhesion was observed.

This could also be influenced by the topographic characteristics of the film surfaces, which are known to affect the adhesion process $[19,53,54]$, being greater when the surface is rough $[55,56]$. An increase in surface roughness stimulates the bacterial bond due to the increased contact area between the bacterial cells and the material's surface [54].

Park et al. [57] evaluated the antimicrobial activity of chitosan-LDPE films, against E. coli, L. monocytogenes and S. enteritidis by observing bacterial growth in the films with the lowest chitosan concentration. The antimicrobial action of chitosan may be due to its stacking on the surface of the bacterial cell wall, blocking the nutritional supply by changing the permeability of the cell wall. When the amount of chitosan released from the film matrix is insufficient, bacterial inhibition is limited or inexistent. Park et al. report that small concentrations of chitosan were unable to maintain lethal conditions against microorganisms and without complete inhibition, the recovery of microbial cells occurred over time [57].

Another explanation of our results obtained in the antimicrobial analysis may be due to the presence of sodium hyaluronate. Tsai and Su [58] suggested that the presence of sodium reduces chitosan's activity against $E$. coli.

Sodium hyaluronate has an important effect on films and the low antibacterial activity may be due to a low density of CHT in the most superficial layer of the sample, leaving the HA exposed, promoting bacterial adhesion $[59,60]$.

Raafat et al. [51] conclude that the broth microdilution technique is the most appropriate to evaluate the potency of an antimicrobial agent by estimating the MIC (minimum inhibitory concentration), unlike the methods based on agar, so the bacterial growth should be well chosen, to avoid unfavorable interaction with chitosan.

Figure 10 shows the antibacterial activity of PEGDE3 and GA crosslinked CHT/HNa $15 \%$ films against $S$. tiphimurium. Although all films exhibited microbial growth, this was lower on chitosan films with PEGDE and glutaraldehyde (low intensity red-pink color). This effect could be explained for PEGDE crosslinked sample as the higher crosslinking density achieved did not expose hyaluronic acid molecules or because the incorporation of hydrophilic crosslinking agents did not allow bacterial adhesion as reported for other fungi [61]. Even when the method used here for antibacterial assessment is not quantitative, it has been used previous by others [62]. However, a possible limitation of the method is due to the high-water absorbency of the samples containing HNa leading to an antifouling behavior rather that an antibacterial behavior as it is known that bacterial do not adhere to highly hydrophilic surfaces. In the supplementary information section (S5), the swelling behavior of HNa-free crosslinked CHT films is reported. 


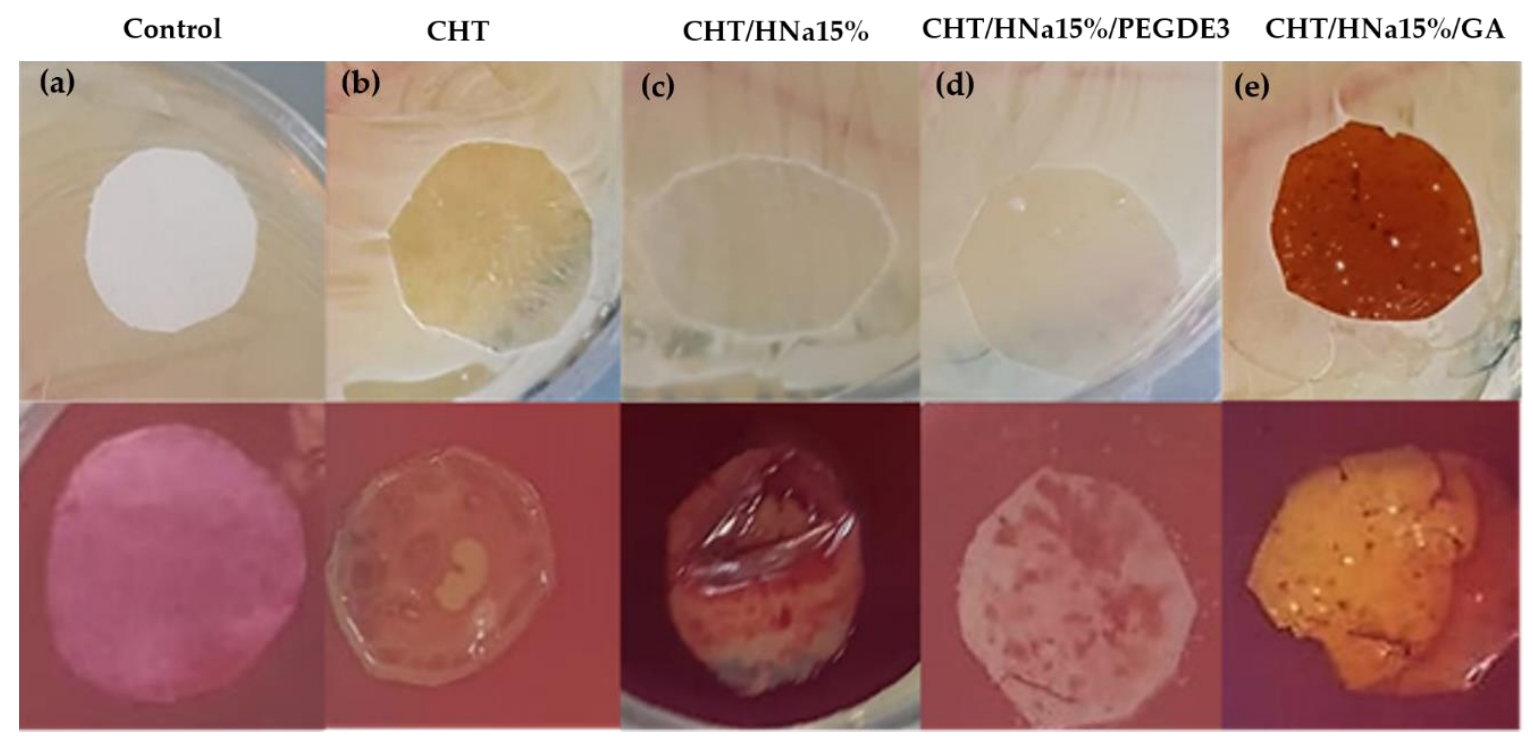

Figure 10. Antimicrobial activity against S. tiphimurium of chitosan discs; (a) Control, (b) CHT, (c) CHT/HNa15, (d) $\mathrm{CHT} / \mathrm{HNa} 15 \% /$ PEDGE3, (e) CHT/HNa15\%/GA. Before $24 \mathrm{~h}$ (top) and after $24 \mathrm{~h}$ (bottom) of inoculation.

For the case of GA crosslinked samples, it is possible that residual aldehyde led to a cytotoxic bacterial effect as it is used for disinfection of medical equipment or because unreacted terminal aldehyde groups are able to interact with functional groups on the bacterial membrane. Therefore, it can be suggested that there is partial antibacterial activity, but further experiments are needed to confirm this.

A final limitation of our study is related to the degradation behavior of these films. However, in supplementary information S6 section, the degradation in phosphate saline buffer of HNa-free crosslinked CHT films is reported.

\section{Conclusions}

The presence of sodium hyaluronate on chitosan was demonstrated by FTIR, Raman, XPS, and XRD. These techniques also allowed to identify the crosslinking potential of PEGDE not only for chitosan but also hyaluronic acid. The addition of a second biocompatible polymer ( $\mathrm{HNa}$ ) to chitosan did not affect degradation temperature as demonstrated by TGA experiments but it reduced its crystallinity as showed by XRD. In fact, crosslinking with PEGDE to CHT-HNa (15\%) blends increased thermal decomposition $\left(\mathrm{T}_{\mathrm{d} 2}\right)$ possibly due to complex formation and/or the formation of an interpenetrated polymer network.

CHT-HNa films showed better adhesion and cell viability with $\mathrm{HNa}(15 \%)$ when crosslinked with PEGDE1, i.e., at low concentration of the crosslinking agent. However, an excess of $\mathrm{HNa}(30 \%)$ did not improve their cell viability even when the surface roughness was increased. In contrast, glutaraldehyde crosslinked samples did benefit from the addition of hyaluronic acid by lowering their DMEM contact angle.

Crosslinked blends of CHT and HNa did not show antibacterial activity towards Escherichia coli, Enterococcus faecalis, and Staphylococcus aureus but a low to mild response against Salmonella typhimurion. This latter behavior was achieved only with high crosslinking concentrations of PEGDE and in the presence of glutaraldehyde with a CHT of medium molecular weight CHT $\left(223,332 \mathrm{~g} \mathrm{~mol}^{-1}\right)$ and a degree of deacetylation of $84.1 \%$. These results stress the importance of the properties of chitosan and the type of strain used to assess the claimed antibacterial behavior of chitosan.

Nonetheless, its non-sticky nature can be further used in the treatment of ulcers (oral thrush), in which not only a low to mild antibacterial activity is needed but also reparative properties are required in the oral mucosa. In this sense, crosslinking with PEGDE will be beneficial because it retains hyaluronic acid, a compound highly soluble in water and that can be easily dissolved when it is not chemically bound to chitosan. 
Supplementary Materials: The following are available online at https:/ / www.mdpi.com/2076-341 7/11/3/1267/s1, Figure S1: Individual FTIR spectra of PEGDE crosslinked CHT films with HNa 15\% and HNa 30\%. Figure S2: Pristine CHT Raman spectra. Figure S3: Pristine HNa Raman spectra Figure S4: XPS scans for C, O and N, of chitosan/HNa films. S5 Swelling behaviour of HNa-free PEGDE crosslinked CHT films. S6 Phosphate buffer saline mass loss of HNa-free PEGDE crosslinked CHT films.

Author Contributions: All authors collaborated in the design of the research study and manuscript writing. All authors have read and agreed to the published version of the manuscript.

Funding: This work was supported by the Consejo Nacional de Ciencia y Tecnología (CONACYT) under grants projects 248378, 1360, 268595, 283972 and the PhD scholarship 339277.

Institutional Review Board Statement: Not applicable.

Informed Consent Statement: Not applicable.

Data Availability Statement: The data presented in this study are available on request from the corresponding author. The data are not publicly available due to its content is part of a PhD Thesis.

Acknowledgments: The authors thank Patricia Quintana and Daniel Aguilar Treviño for XRD and Wilian Cauich for XPS experiments at Laboratorio Nacional de Nano y Biomateriales (LANBIO), Cinvestav-IPN, Unidad Mérida (Projects FOMIX-Yucatan 2008-108160 and CONACYT LAB-2009-01 no. 123913). The authors also wish to thank Alejandro May Pat for AFM analysis.

Conflicts of Interest: The authors declare no conflict of interest. The founding sponsors had no role in the design of the study; in the collection, analyses, or interpretation of data; in the writing of the manuscript; or in the decision to publish the results.

\section{References}

1. de Britto, D.; Campana-Filho, S.P. Kinetics of the thermal degradation of chitosan. Thermochim. Acta 2007, 465, 73-82. [CrossRef]

2. Rinaudo, M. Chitin and chitosan: Properties and applications. Prog. Polym. Sci. 2006, 31, 603-632. [CrossRef]

3. Tang, H.; Zhang, P.; Kieft, T.L.; Ryan, S.J.; Baker, S.M.; Wiesmann, W.P.; Rogelj, S. Antibacterial action of a novel functionalized chitosan-arginine against Gram-negative bacteria. Acta Biomater. 2010, 6, 2562-2571. [CrossRef] [PubMed]

4. Youssef, A.M.; Abou-yousef, H.; El-sayed, S.M.; Kamel, S. Mechanical and antibacterial properties of novel high performance chitosan/nanocomposite films. Int. J. Biol. Macromol. 2015, 76, 25-32. [CrossRef] [PubMed]

5. Muzzarelli, R.A.A.; Orlandini, F.; Pacetti, D.; Boselli, E.; Frega, N.G.; Tosi, G.; Muzzarelli, C. Chitosan taurocholate capacity to bind lipids and to undergo enzymatic hydrolysis: An in vitro model. Carbohydr. Polym. 2006, 66, 363-371. [CrossRef]

6. Feng, J.; Zhao, L.; Yu, Q. Receptor-mediated stimulatory effect of oligochitosan in macrophages. Biochem. Biophys. Res. Commun. 2004, 317, 414-420. [CrossRef]

7. Salah, R.; Michaud, P.; Mati, F.; Harrat, Z.; Lounici, H.; Abdi, N.; Drouiche, N.; Mameri, N. Anticancer activity of chemically prepared shrimp low molecular weight chitin evaluation with the human monocyte leukaemia cell line, THP-1. Int. J. Biol. Macromol. 2013, 52, 333-339. [CrossRef]

8. Mujtaba, M.; Morsi, R.E.; Kerch, G.; Elsabee, M.Z.; Kaya, M.; Labidi, J.; Khawar, K.M. Current advancements in chitosan-based film production for food technology; A review. Int. J. Biol. Macromol. 2019, 121, 889-904. [CrossRef]

9. Walimbe, T.; Panitch, A.; Sivasankar, P.M.; Lafayette, W. A Review of Hyaluronic Acid and Hyaluronic Acid-based Hydrogels for Vocal Fold Tissue Engineering. J. Voice 2017, 31, 416-423. [CrossRef]

10. Mathews, S.; Mathew, S.A.; Gupta, P.K.; Bhonde, R.; Totey, S. Glycosaminoglycans enhance osteoblast differentiation of bone marrow derived human mesenchymal stem cells. Tissue Eng. Regen. Med. 2014, 8, 143-152. [CrossRef]

11. Chircov, C.; Grumezescu, A.M.; Bejenaru, L.E. Hyaluronic acid-based scaffolds for tissue engineering. Rom. J. Morphol. Embryol. 2018, 59, 71-76. [PubMed]

12. Croll, T.I.; Connor, A.J.O.; Stevens, G.W.; Cooper-white, J.J. A Blank Slate? Layer-by-Layer Deposition of Hyaluronic Acid and Chitosan onto Various Surfaces. Biomacromolecules 2006, 7, 1610-1622. [CrossRef] [PubMed]

13. Nasti, A.; Zaki, N.M.; De Leonardis, P.; Ungphaiboon, S.; Sansongsak, P.; Rimoli, M.G.; Tirelli, N. Chitosan/TPP and Chitosan/TPP-hyaluronic Acid Nanoparticles: Systematic Optimisation of the Preparative Process and Preliminary Biological Evaluation. Pharm. Res. 2009, 26, 1918-1930. [CrossRef] [PubMed]

14. Yamane, S.; Iwasaki, N.; Kasahara, Y.; Harada, K.; Majima, T.; Monde, K.; Nishimura, S.; Minami, A. Effect of pore size on in vitro cartilage formation using chitosan-based hyaluronic acid hybrid polymer fibers. J. Biomed. Mater. Res. A 2007, 81, 586-593. [CrossRef]

15. Mohandas, A.; Anisha, B.S.; Chennazhi, K.P.; Jayakumar, R. Chitosan-hyaluronic acid/VEGF loaded fibrin nanoparticles composite sponges for enhancing angiogenesis in wounds. Colloids Surf. B Biointerfaces 2015, 127, 105-113. [CrossRef] 
16. Kuotlusy, T.; Oktay, B.; Apohan, N.K.; Süleymanoğlu, M.; Kuruca, S.E. Chitosan-co-Hyaluronic acid porous cryogels and their application in tissue engineering. Int. J. Biol. Macromol. 2017, 103, 366-378. [CrossRef]

17. Tan, H.; Chu, C.R.; Payne, K.A.; Marra, K.G. Injectable in situ forming biodegradable chitosan-hyaluronic acid based hydrogels for cartilage tissue engineering. Biomaterials 2009, 30, 2499-2506. [CrossRef]

18. Zakeri, A.; Mirzaei, E.; Ghasemi, Y.; Amin, M.; Kouhbanani, J. Hyaluronic acid coated electrospun chitosan-based nano fi bers prepared by simultaneous stabilizing and coating. Int. J. Biol. Macromol. 2019, 138, 403-411.

19. Muzzio, N.E.; Pasquale, M.A.; Diamanti, E.; Gregurec, D.; Moro, M.M.; Azzaroni, O.; Moya, S.E. Enhanced antiadhesive properties of chitosan/hyaluronic acid polyelectrolyte multilayers driven by thermal annealing: Low adherence for mammalian cells and selective decrease in adhesion for Gram-positive bacteria. Mater. Sci. Eng. C 2017, 80, 677-687. [CrossRef]

20. Khan, F.; Thuy, D.; Pham, N.; Folarin, S. Chitosan and their derivatives: Antibiofilm drugs against pathogenic bacteria. Colloids Surf. B Biointerfaces 2020, 185, 110627. [CrossRef]

21. Zheng, L.; Zhu, J. Study on antimicrobial activity of chitosan with different molecular weights. Carbohydr. Polym. 2003, 54, 527-530. [CrossRef]

22. Zou, P.; Yang, X.; Wang, J.; Li, Y.; Yu, H.; Zhang, Y.; Liu, G. Advances in characterisation and biological activities of chitosan and chitosan oligosaccharides. Food Chem. 2016, 190, 1174-1181. [CrossRef] [PubMed]

23. Hu, H.; Ye, B.; Lv, Y.; Zhang, Q. Preparing antibacterial and in-situ formable double crosslinking chitosan/hyaluronan composite hydrogels. Mater. Lett. 2019, 254, 17-20. [CrossRef]

24. Rodríguez López, A.d.L.; Lee, M.R.; Ortiz, B.J.; Gastfriend, B.D.; Whitehead, R.; Lynn, D.M.; Palecek, S.P. Preventing S. aureus biofilm formation on titanium surfaces by the release of antimicrobial $\beta$-peptides from polyelectrolyte multilayers. Acta Biomater. 2019, 93, 50-62. [CrossRef]

25. Vale, A.C.; Pereira, P.; Barbosa, A.M.; Torrado, E.; Mano, J.F.; Alves, N.M. Antibacterial free-standing polysaccharide composite films inspired by the sea. Int. J. Biol. Macromol. 2019, 133, 933-944. [CrossRef]

26. Li, X.F.; Feng, X.Q.; Yang, S.; Fu, G.Q.; Wang, T.P.; Su, Z.X. Chitosan kills Escherichia coli through damage to be of cell membrane mechanism. Carbohydr. Polym. 2010, 79, 493-499. [CrossRef]

27. Yu, W.; Koc, J.; Finlay, J.A.; Clarke, J.L.; Clare, A.S.; Rosenhahn, A.; Yu, W.; Koc, J.; Finlay, J.A.; Clarke, J.L.; et al. Layer-by-layer constructed hyaluronic acid/chitosan multilayers as antifouling and fouling-release coatings. Biointerphases 2019, $14,051002$. [CrossRef]

28. Chuc-Gamboa, M.G.; Vargas-Coronado, R.F.; Cervantes-Uc, J.M.; Cauich-Rodríguez, J.V.; Escobar-García, D.M.; Pozos-Guillén, A.; del Barrio, J.S.R. The Effect of PEGDE Concentration and Temperature on Physicochemical and Biological Properties of Chitosan. Polymers 2019, 11, 1830. [CrossRef]

29. Deepthi, S.; Jeevitha, K.; Nivedhitha Sundaram, M.; Chennazhi, K.P.; Jayakumar, R. Chitosan-hyaluronic acid hydrogel coated poly(caprolactone) multiscale bilayer scaffold for ligament regeneration. Chem. Eng. J. 2015, 260, 478-485. [CrossRef]

30. Wang, Y.; Guo, L.; Ren, L.; Yin, S.; Ge, J.; Gao, Q.; Luxbacher, T.; Luo, S. A study on the performance of hyaluronic acid immobilized chitosan film. Biomed. Mater. 2009, 4, 035009. [CrossRef]

31. Hwang, H.D.; Cho, H.J.; Balakrishnan, P.; Chung, C.W.; Yoon, I.S.; Oh, Y.K.; Byun, Y.; Kim, D.D. Cross-linked hyaluronic acid-based flexible cell delivery system: Application for chondrogenic differentiation. Colloids Surf. B Biointerfaces 2012, 91, 106-113. [CrossRef] [PubMed]

32. Zhang, K.; Peschel, D.; Helm, J.; Groth, T.; Fischer, S. FT Raman investigation of novel chitosan sulfates exhibiting osteogenic capacity. Carbohydr. Polym. 2011, 83, 60-65. [CrossRef]

33. Aryaei, A.; Jayatissa, A.H.; Jayasuriya, A.C. Mechanical and biological properties of chitosan/carbon nanotube nanocomposite films. J. Biomed. Mater. Res. Part A 2014, 102A, 2704-2712. [CrossRef] [PubMed]

34. Synytsya, A.; Synytsya, A.; Alexa, P.; Wagner, R.; Davídková, M.; Volka, K. Raman spectroscopic study on sodium hyaluronate: An effect of proton and $\gamma$ irradiation. J. Raman Spectrosc. 2011, 42, 544-550. [CrossRef]

35. Essendoubi, M.; Gobinet, C.; Reynaud, R.; Angiboust, J.F.; Manfait, M.; Piot, O. Human skin penetration of hyaluronic acid of different molecular weights as probed by Raman spectroscopy. Ski. Res. Technol. 2016, 22, 55-62. [CrossRef]

36. Réeff, J.; Gaignaux, A.; Goole, J.; De Vriese, C.; Amighi, K. New sustained-release intraarticular gel formulations based on monolein for local treatment of arthritic diseases. Drug Dev. Ind. Pharm. 2013, 39, 1731-1741.

37. Naito, P.K.; Ogawa, Y.; Kimura, S.; Iwata, T.; Wada, M. Crystal transition from hydrated chitosan and chitosan/monocarboxylic acid complex to anhydrous chitosan investigated by X-ray diffraction. J. Polym. Sci. Part. B Polym. Phys. 2015, 53, 1065-1069. [CrossRef]

38. Mao, S.; Shuai, X.; Unger, F.; Simon, M.; Bi, D.; Kissel, T. The depolymerization of chitosan: Effects on physicochemical and biological properties. Int. J. Pharm. 2004, 281, 45-54. [CrossRef]

39. Sheehan, J.K.; Atkins, E.D.T. X-ray fibre diffraction study of conformational changes in hyaluronate induced in the presence of sodium, potassium and calcium cations. Int. J. Biol. Macromol. 1983, 5, 215-221. [CrossRef]

40. Lee, C.-M.; Yang, S.-W.; Jung, S.-C.; Kim, B.-H. Oxygen Plasma Treatment on 3D-Printed Chitosan/Gelatin/Hydroxyapatite Scaffolds for Bone Tissue Engineering. J. Nanosci. Nanotechnol. 2017, 17, 2747-2750. [CrossRef]

41. Bettelheim, F.A. Crystalline Sodium Hyaluronate. Nature 1958, 182, 1301-1302. [CrossRef] [PubMed]

42. Nath, S.D.; Abueva, C.; Kim, B.; Lee, B.T. Chitosan-hyaluronic acid polyelectrolyte complex scaffold crosslinked with genipin for immobilization and controlled release of BMP-2. Carbohydr. Polym. 2015, 115, 160-169. [CrossRef] [PubMed] 
43. Lewandowska, K.; Sionkowska, A.; Grabska, S.; Kaczmarek, B.; Michalska, M. The miscibility of collagen/hyaluronic acid/chitosan blends investigated in dilute solutions and solids. J. Mol. Liq. 2016, 220, 726-730. [CrossRef]

44. Romero-Vargas Castrillón, S.; Lu, X.; Shaffer, D.L.; Elimelech, M. Amine enrichment and poly(ethylene glycol) (PEG) surface modification of thin-film composite forward osmosis membranes for organic fouling control. J. Memb. Sci. 2014, 450, 331-339. [CrossRef]

45. Li, L.; Wang, N.; Jin, X.; Deng, R.; Nie, S.; Sun, L.; Wu, Q.; Wei, Y.; Gong, C. Biodegradable and injectable in situ cross-linking chitosan-hyaluronic acid based hydrogels for postoperative adhesion prevention. Biomaterials 2014, 35, 3903-3917. [CrossRef]

46. Kaczmarek, B.; Sionkowska, A.; Łukowicz, K.; Maria Osyczka, A. The cells viability study on the composites of chitosan and collagen with glycosaminoglycans isolated from fish skin. Mater. Lett. 2017, 206, 166-168. [CrossRef]

47. Chen, C.H.; Chen, S.H.; Mao, S.H.; Tsai, M.J.; Chou, P.Y.; Liao, C.H.; Chen, J.P. Injectable thermosensitive hydrogel containing hyaluronic acid and chitosan as a barrier for prevention of postoperative peritoneal adhesion. Carbohydr. Polym. 2017, 173, 721-731. [CrossRef]

48. Ström, A.; Larsson, A.; Okay, O. Preparation and physical properties of hyaluronic acid-based cryogels. J. Appl. Polym. Sci. 2015, 132, 1-11. [CrossRef]

49. Casimiro, M.H.; Gomes, S.R.; Rodrigues, G.; Leal, J.P.; Ferreira, L.M. Chitosan/Poly(vinylpyrrolidone) Matrices Obtained by Gamma-Irradiation for Skin Scaffolds: Characterization and Preliminary Cell Response Studie. Materials 2018, 11, 2535. [CrossRef]

50. Bellich, B.; D’Agostino, I.; Semeraro, S.; Gamini, A.; Cesàro, A. “The Good, the Bad and the Ugly" of Chitosans Barbara. Mar. Drugs 2016, 14, 99. [CrossRef]

51. Raafat, D.; Sahl, H. Chitosan and its antimicrobial potential-A critical literature survey. Microb. Biotechnol. 2009 , 2, 186-201. [CrossRef] [PubMed]

52. Gritsch, L.; Lovell, C.; Goldmann, W.H.; Boccaccini, A.R. Fabrication and characterization of copper (II)-chitosan complexes as antibiotic-free antibacterial biomaterial. Carbohydr. Polym. 2018, 179, 370-378. [CrossRef] [PubMed]

53. Hsu, L.; Fang, J.; Borca-tasciuc, D.; Worobo, R.; Moraru, C.I.; Polytechnic, R. The Effect of Micro- and Nanoscale Topography on the Adhesion of Bacterial Cells to Solid Surfaces. Appl. Environ. Microbiol 2013, 79, 2703-2712. [CrossRef] [PubMed]

54. Song, F.; Koo, H.; Ren, D. Effects of Material Properties on Bacterial Adhesion and Biofilm Formation. J. Dent. Res. 2015, 94, 1027-1034. [CrossRef] [PubMed]

55. Lüdecke, C.; Roth, M.; Yu, W.; Horn, U.; Bossert, J.; Jandt, K.D. Nanorough titanium surfaces reduce adhesion of Escherichia coli and Staphylococcus aureus via nano adhesion points. Colloids Surf. B Biointerfaces 2016, 145, 617-625. [CrossRef] [PubMed]

56. Liu, L.; Ercan, B.; Sun, L.; Ziemer, K.S.; Webster, T.J. Understanding the Role of Polymer Surface Nanoscale Topography on Inhibiting Bacteria Adhesion and Growth. ACS Biomater. Sci. Eng. 2016, 2, 122-130. [CrossRef]

57. Park, S.; Marsh, K.S.; Dawson, P. Application of chitosan-incorporated LDPE film to sliced fresh red meats for shelf life extension. Meat Sci. 2010, 85, 493-499. [CrossRef]

58. Tsai, G.; Su, W. Antibacterial Activity of Shrimp Chitosan against Escherichia coli. J. Food Prot. 1999, 62, 239-243. [CrossRef]

59. Hernandez-montelongo, J.; Lucchesi, E.G.; Gonzalez, I.; Macedo, W.A.A. Hyaluronan/chitosan nanofilms assembled layerby-layer and their antibacterial effect: A study using Staphylococcus aureus and Pseudomonas aeruginosa. Colloids Surf. B Biointerfaces 2016, 141, 499-506. [CrossRef]

60. Vasconcellos, F.C.; Swiston, A.J.; Beppu, M.M.; Cohen, R.E.; Rubner, M.F. Bioactive Polyelectrolyte Multilayers: Hyaluronic Acid Mediated B Lymphocyte Adhesion. Biomacromolecules 2010, 11, 2407-2414. [CrossRef]

61. Mohamed, N.A.; Fahmy, M.M. Synthesis and antimicrobial activity of some novel cross-linked chitosan hydrogels. Int. J. Mol. Sci. 2012, 13, 11194-11209. [CrossRef] [PubMed]

62. Perumal, A.B.; Sellamuthu, P.S.; Nambiar, R.B.; Sadiku, E.R. Development of polyvinyl alcohol/chitosan bio-nanocomposite films reinforced with cellulose nanocrystals isolated from rice straw. Appl. Surf. Sci. 2018, 449, 591-602. [CrossRef] 